\title{
Evaluation of the New Photosensitizer Stakel (WST-11) for Photodynamic Choroidal Vessel Occlusion in Rabbit and Rat Eyes
}

\author{
Marianne Berdugo, ${ }^{1}$ Riad A. Bejjani, ${ }^{1}$ Fatemeb Valamanesh, ${ }^{1,2}$ Michele Savoldelli, ${ }^{1,3}$ \\ Jean-Claude Jeanny, ${ }^{1}$ Dominique Blanc, ${ }^{4}$ Herve Ficheux, ${ }^{4}$ Avigdor Scherz, ${ }^{5}$ \\ Yoram Salomon, ${ }^{5}$ David BenEzra, ${ }^{1}$ and Francine Behar-Coben ${ }^{1,2,3}$
}

Purpose. To evaluate the photodynamic potential of a new hydrosoluble photosensitizer (WST-11, Stakel; Steba Biotech, Toussus-Le-Noble, France), for use in occlusion of normal choroidal vessels in the rabbit eye and $\mathrm{CNV}$ (choroidal neovascularization) in the rat eye.

Methods. Occlusive and nonocclusive parameters of Stakel and verteporfin photodynamic therapy (PDT) were investigated in pigmented rabbits. Eyes were followed by fluorescein angiography (FA) and histology at various intervals after PDT.

Results. When occlusive parameters (fluence of $50 \mathrm{~J} / \mathrm{cm}^{2}, 5$ $\mathrm{mg} / \mathrm{kg}$ drug dose and DLI [distance to light illumination] of 1 minute) were used, Stakel PDT was efficient immediately after treatment without associated structural damage of the RPE and retina overlying the treated choroid in the rabbit eye. Two days later, total occlusion of the choriocapillaries was seen in $100 \%$ of the treated eyes, along with accompanying histologic structural changes in the overlying retina. When the occlusive parameters (fluence, $100 \mathrm{~J} / \mathrm{cm}^{2}$; drug dose, $12 \mathrm{mg} / \mathrm{m}^{2}$; and DLI, 5 minutes) of verteporfin PDT were used, occlusion of the choriocapillaries was observed in $89 \%$ of the treated eyes. Histology performed immediately after treatment demonstrated structural damage of the overlying retina and RPE layer. Weaker, nonocclusive Stakel PDT parameters $\left(25 \mathrm{~J} / \mathrm{cm}^{2}, 5\right.$ $\mathrm{mg} / \mathrm{kg}$, and DLI of 10 minutes) did not induce choriocapillary occlusion or retinal lesions on FA or histology. Weaker, nonocclusive verteporfin PDT parameters $\left(10 \mathrm{~J} / \mathrm{cm}^{2}, 0.2 \mathrm{mg} / \mathrm{kg}\right.$, and DLI of 5 minutes) did not induce choriocapillary occlusion. However, histology of these eyes showed the presence of damage in the retinal and choroidal tissues. Moreover, preliminary results indicate that selective $\mathrm{CNV}$ occlusion can be achieved with Stakel PDT in the rat eye.

Conclusions. Unlike verteporfin PDT, Stakel PDT does not cause direct damage to the RPE cell layer or retina. These

From the ${ }^{1}$ Centre de Recherche des Cordeliers, Physiopathology of Ocular Diseases: Therapeutic Innovations, UMR S 872, Université Paris Descartes, Paris, France; the ${ }^{2}$ Rothschild Foundation, Paris, France; the ${ }^{3}$ Department of Ophthalmology, Hôtel-Dieu Paris, Paris, France; ${ }^{4}$ Steba Biotech, Rehovot, Israel; and the ${ }^{5}$ Weizmann Institute of Science, Rehovot, Israel.

Supported by a research grant from Negma Laboratories.

Submitted for publication June 21, 2007; revised August 19 and November 30, 2007; accepted February 21, 2008.

Disclosure: M. Berdugo, None; R. Bejjani, None; F. Valamanesh, None; M. Savoldelli, None; J.C. Jeanny, None; D. Blanc, Steba Biotech (E); H. Ficheux, Steba Biotech (E); A. Scherz, Negma Laboratories (F), P; Y. Salomon, Negma Laboratories (F), P; D. BenEzra, None; F. Behar-Cohen, None

The publication costs of this article were defrayed in part by page charge payment. This article must therefore be marked "advertisement" in accordance with 18 U.S.C. $\$ 1734$ solely to indicate this fact.

Corresponding author: Francine Behar-Cohen, UMR S 872, 15 rue de l'Ecole de Médecine, 75006 Paris, France; francine.behar@gmail.com. observations indicate that Stakel PDT may have a high potential for beneficial therapeutic outcomes in treatment of AMD. (Invest Ophthalmol Vis Sci. 2008;49:1633-1644) DOI:10.1167/ iovs.07-0767

Dhotodynamic therapy (PDT) has been developed with the purpose of inducing localized vascular occlusion of the newly formed vascular membranes emanating from the choroid (choroidal neovascularization $[\mathrm{CNV}]$ ). In certain patients with age-related macular degeneration (AMD), PDT with verteporfin (Visudyne; Novartis, Basel, Switzerland) reduced significantly the risk of visual loss when compared with the risk in untreated patients. ${ }^{1-5}$ The mechanism of action of PDT is thought to involve the release of reactive oxygen radicals that damage endothelial cells and activate the blood-clotting cascade,${ }^{6}$ leading to the formation of thrombi within the vessel lumen. $^{7}$

For the treatment of $\mathrm{CNV}$, highly selective parameters (laser fluence, photosensitizer dose, and distance to light illumination [DLI]) must be established, to enable efficient targeting of the pathologic vessels with reduced secondary damage to healthy retinal and choroidal tissues. Verteporfin is, at present, the only U.S. Food and Drug Administration (FDA)-approved compound for clinical use. It is a lipophilic compound (BPDMA) injected as a liposomal formulation. Repeated treatments are generally necessary to achieve the desired therapeutic effects. ${ }^{8}$ In these cases, the danger of collateral tissue damage is enhanced and may become a significant side effect of treatment. Recently both preclinical and clinical studies have confirmed that verteporfin PDT results in damage to retinal pigment epithelial (RPE) cells associated with photoreceptor lesions. ${ }^{-11}$ These collateral secondary effects, along with the emergence of efficient intraocular anti-VEGF therapies, have caused a recent dramatic reduction in the routine use of PDT for the treatment of patients with wet AMD. To enhance the specificity of PDT's effects and minimize the potential collateral damage, targeted verteporfin ${ }^{12}$ and other groups of photosensitizers have been tested. ${ }^{13-15}$

Palladium-substituted bacteriochlorophyll derivatives are new photosensitizers with high absorbance in the near infrared. WST-09 (Tookad; Negma-Lerads, Magny-Les-Hameaux, France) has been developed for cancer treatment. ${ }^{16-18}$ It diffuses to collateral tissues and has no compartmental localization within the eye. In contrast, another newly discovered derivative, WST-11 (Stakel; Steba Biotech, Toussus-Le-Noble, France), remains in the vascular compartment, with minimal diffusion to the surrounding tissues. ${ }^{19}$ Therefore, our surmise was that vascular-targeted photodynamic therapy (VTP) with Stakel might induce less secondary collateral damage than those presently observed with lipophilic photosensitizer compounds.

WST-11 (Stakel) is a negatively charged, water-soluble derivative with maximum absorption wavelength in the near infrared $(753 \mathrm{~nm})$ and rapid clearance from the body $t_{[1 / 2]}=$ 
0.37 hour for a $10-\mathrm{mg} / \mathrm{kg}$ drug dose in the rat and $t_{[1 / 2]}=0.51$ hour, 1 hour, and 2.65 hours for $1.25-, 2.5-$, and $5-\mathrm{mg} / \mathrm{kg}$ drug doses, respectively. It binds to serum albumin and has potent antivascular activity through the generation of hydroxyl radicals when stimulated by the proper light wavelength. ${ }^{20,21}$ In this article, we report our observations regarding the effects of WST-11 PDT on the normal rabbit eye and compare them to those observed with the use of verteporfin-PDT. We also report preliminary observations of the effect of Stakel PDT on laserinduced $\mathrm{CNV}$ in the rat eye.

\section{Materials ANd Methods}

\section{Animals}

A total of 78 pigmented Fauve de Bourgogne rabbits (10-12 weeks old, 2.5-3 kg; Elevage des Pins, Epeigne-sur-Dême, France) were used. All experiments were conducted in accordance with the ARVO Statement for the Use of Animals in Ophthalmic and Vision Research and institutional guidelines regarding animal experimentation. Only one eye per rabbit was treated. The animals were anesthetized with a mixture of xylazine $(0.1 \mathrm{~mL} / \mathrm{kg})$ and ketamine $(0.1 \mathrm{~mL} / \mathrm{kg})$. At the end of the experiments, the treated rabbits were killed by a lethal intracardiac injection of pentobarbital.

Six rabbits received two different doses of Stakel and were used to study the pharmacokinetics and elimination rates of the drug from the blood. Forty-five rabbits were used for the study of Stakel PDT effects and controls, and 27 were used for the study of verteporfin PDT effects. We used various treatment parameters to make comparisons between the effects of Stakel PDT and those of verteporfin PDT.

\section{Lasers}

For Stakel and verteporfin PDT, illumination was performed with 753and 689-nm diode lasers, respectively (CeramOptec, Bonn, Germany). The laser source was connected to a slit lamp (model BQ 900; HaagStreit, Köniz, Switzerland). This diode laser had a constant and homogenous irradiance.

For Stakel and verteporfin PDT, the laser spot size was set at 2.7 $\mathrm{mm}$ on the cornea and $1.8 \mathrm{~mm}$ on the fundus. Laser spots were applied below and in the immediate vicinity of the optic disc, away from the myelinated retinal nerve fibers.

\section{Photosensitizers}

Stakel (WST-11). Stakel (palladium-bacteriopheophorbide monolysine taurine) is a pure, stable, black-purple, novel, crystalline, water-soluble bacteriochlorophyll derivative that has the following structural formula:

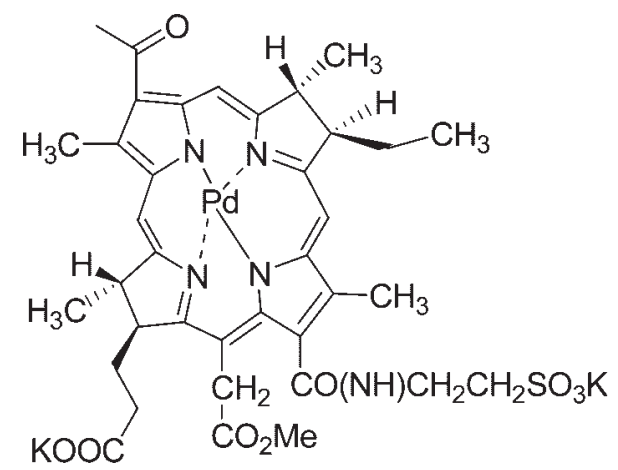

Its molecular weight is 916 , and it has four main absorption peaks $(750,530,385$, and $330 \mathrm{~nm})$. The strongest absorbance of light is near the infrared $(\approx 750 \mathrm{~nm})$ where tissue transmittance is highest. This study was performed with the same batch of product.
Protein-Binding Affinity. Characterization of WST-11 binding to plasma proteins was determined with human or rabbit blood.

Determination of Concentrations. Stakel concentrations were determined by an inductive coupled plasma mass spectroscopy (ICP-MS) method, as previously described. ${ }^{19}$

Experimental PDT Protocol Design. For the PDT experiments, the Stakel powder was diluted in an endotoxin-free sterile glucose (5\%)-saline solution at a concentration of $10 \mathrm{mg} / \mathrm{mL}$ and used immediately. When protected from light, this formulation remains stable for 3 hours at $4^{\circ} \mathrm{C}$. To calculate the volume to be injected, adjustment was made according to the rabbit's weight. The appropriate volume solution was injected intravenously as a bolus via the marginal ear vein.

Pharmacokinetics in the Rabbit. Three rabbits received a dose of $5 \mathrm{mg} / \mathrm{kg}$ Stakel and three received a dose of $2.5 \mathrm{mg} / \mathrm{kg}$. Blood aliquots of $200 \mu \mathrm{L}$ were collected from the contralateral marginal ear vein in small vials containing heparin at the following time points: before the Stakel injection (time -1); at the end of the injection (time 0 ); and at 1, 5, 10, 15, 30, and 60 minutes afterward. The blood samples were lyophilized and kept at $4^{\circ} \mathrm{C}$ until testing for Stakel was performed.

Control for WST-11 Injection: No Illumination. As the control for the potential effect of Stakel on the retinal and choroid vessels, three rabbits received $5 \mathrm{mg} / \mathrm{kg}$ Stakel and three received 2.5 $\mathrm{mg} / \mathrm{kg}$. Two and 8 days after the injection, fluorescein angiography (FA) was performed and its patterns recorded. The rabbits were killed on day 8 .

Control for Laser Illumination. The effect of laser illumination (without drug injection) at $753 \mathrm{~nm}$ was evaluated at a fluence of $25 \mathrm{~J} / \mathrm{cm}^{2}$ (irradiance, $300 \mathrm{~mW} / \mathrm{cm}^{2}, 83$ seconds) in four rabbits (four eyes) and at a fluence of $50 \mathrm{~J} / \mathrm{cm}^{2}$ (irradiance, $600 \mathrm{~mW} / \mathrm{cm}^{2}, 83$ seconds) in four additional rabbits (four eyes). The laser was applied by using a PDT laser Lens (Volk Optical Inc., Mentor, OH). Clinical examination of the fundus was performed at the end of the illumination period. Two and 8 days after illumination, FA was performed, the animals killed, and the eyes subjected to histologic examination.

Screening for Acute Vessel Occlusion Parameters. Fifteen rabbits were used for testing the following laser fluence and drug dose combination: group 1, five rabbits were treated with $50 \mathrm{~J} / \mathrm{cm}^{2}$ fluence and $5 \mathrm{mg} / \mathrm{kg}$ Stakel; group 2, five rabbits were treated with $25 \mathrm{~J} / \mathrm{cm}^{2}$ fluence and $5 \mathrm{mg} / \mathrm{kg}$ Stakel; and group 3, five rabbits were treated with $50 \mathrm{~J} / \mathrm{cm}^{2}$ fluence and $2.5 \mathrm{mg} / \mathrm{kg}$ Stakel. PDT in each group was performed at delays between injection to laser illumination (DLI) of 1 , 5,10 , or 15 minutes. Thus, five treatment spots were available for the assessment of each specific combination of fluence drug dose and DLI.

Clinical examination of the fundus was performed at the end of PDT. Fluorescein angiograms were obtained 2 and 8 days after treatment.

Histology and Long-Term PDT Effects. After the screening occlusive data were analyzed, 16 rabbits received PDT parameters of either $5 \mathrm{mg} / \mathrm{kg}$ Stakel at a laser fluence of $50 \mathrm{~J} / \mathrm{cm}^{2}$ and a DLI of 1 minute $(n=8)$ or $5 \mathrm{mg} / \mathrm{kg}$ Stakel at a laser fluence of $25 \mathrm{~J} / \mathrm{cm}^{2}$ and a DLI of 10 minutes $(n=8)$.

Clinical examination of the fundus of each treated rabbit eye was performed at the end of PDT. FA was performed at 2, 8, and 30 days after treatment. For each combination of parameters, two rabbits were killed 2 hours after treatment, two rabbits on day 2, two rabbits on day 8 , and two rabbits on day 30 after PDT. The eyes were immediately enucleated and processed for histology. Semithin sections were prepared, and transmission electron microscopy (TEM) was performed for selected sections.

Verteporfin. The commercially available drug for human use (Visudyne, verteporfin; Novartis) was slowly perfused intravenously for 5 minutes. The dose of verteporfin to be injected for treatment was calculated to conform to the manufacturer's recommended human dose of $6 \mathrm{mg} / \mathrm{m}^{2}$ adjusted for the rabbit body surface. The amount was obtained with the following formula: rabbit body surface area $\left(\mathrm{cm}^{2}\right)=$ $9.5 \times$ (weight in grams). 
Screening for Occlusive Parameters. Screening experiments for the occlusive parameters were performed with a 689-nm laser and a constant DLI of 5 minutes in three groups of rabbits. The DLI of 5 minutes was chosen according to previous pharmacokinetic data published in the rabbit, showing that at this time point, the maximum concentration of the photosensitizer was found in the choriocapillaris with minimal diffusion to the RPE and retina, when compared with later time points. ${ }^{22}$ Group $1(n=9)$ received $12 \mathrm{mg} / \mathrm{m}^{2}$ verteporfin $(0.8 \mathrm{mg} / \mathrm{kg})$ at a fluence of $100 \mathrm{~J} / \mathrm{cm}^{2}$, group $2(n=9)$ received $6 \mathrm{mg} / \mathrm{m}^{2}(0.4 \mathrm{mg} / \mathrm{kg})$ at $50 \mathrm{~J} / \mathrm{cm}^{2}$, and group $3(n=9)$ received $3 \mathrm{mg} / \mathrm{m}^{2}(0.2 \mathrm{mg} / \mathrm{kg})$ at $10 \mathrm{~J} / \mathrm{cm}^{2}$. Clinical examination of the fundus was performed at the end of PDT. FA was performed on days 2,8 , and 30 after treatment. For each combination of PDT parameters, two rabbits were killed 2 hours after PDT, on days 2, 8, and 30 after treatment. The eyes were enucleated and subjected to histology. Transmission electron microscopy was performed in selected sections.

Histology. Enucleated eyes were dissected under a binocular microscope. A 4-mm biopsy punch was used to excise the full thickness of treated zones. Tissues were fixed in glutaraldehyde, processed in cacodylate buffer, and embedded in plastic. Semithin sections were obtained with a microtome and counterstained with hematoxylineosin. These sections were analyzed by phase-contrast microscopy. Specific sites of interest were further processed for TEM. Ultrathin sections were obtained with an ultramicrotome and counterstained with uranyl acetate.

Grading of Histologic Damage. To evaluate the effects of PDT, we used a modified grading scheme based on the principles described previously for the assessment of the side effects of verteporfin PDT in monkey and rat eyes. ${ }^{23,24}$ The following grading system was used: 0 , no histologic damage and/or only mild vasodilatation of choroidal vessels; 1 , damage to the RPE, slight damage to the photoreceptor layer, occasional cell pyknotic changes in the outer nuclear layer (ONL), and/or closure of the choriocapillaries; 2, damage to the RPE, more extensive damage of photoreceptors, choriocapillary closure, and $10 \%$ to $20 \%$ cell pyknosis in the ONL; 3 , same as grade 2 , with $20 \%$ to $50 \%$ cell pyknosis in the ONL; 4 , same as grade 3 , with $>50 \%$ of cell pyknosis in the ONL; and 5, same as grade 4, with structural damage to the inner retinal layers. This scale is mainly based on the intensity of photoreceptor damage and is therefore adequate for the evaluation of retinal collateral effects in eyes receiving nonocclusive PDT parameters.
Effect of Stakel PDT on CNV in the Rat. To evaluate whether Stakel PDT could occlude CNV specifically, we used a laserinduced $\mathrm{CNV}$ model in the rat.

Animals were cared for in accordance with the Directives of the European Community as well as with the ARVO Statement for the Use of Animals in Ophthalmic and Vision Research. Eight Brown Norway rats (Charles River Laboratories, L'Arbresle, France) weighing 230 to $250 \mathrm{~g}$ were used. At the end of the experiments, the rats were killed by intraperitoneal injection of a lethal dose of pentobarbital (Sanofi-Aventis, Paris, France).

Induction of $C N V$. The rats were anesthetized with $0.06 \mathrm{~mL} /$ $100 \mathrm{~g}$ of a 50/50 solution of chlorpromazine (Sanofi-Aventis) and ketamine 1000 (Virbac, Carros, France). Maximum pupil dilation was obtained by repeated instillation of $0.5 \%$ tropicamide (Mydriaticum; Théa, Clermont-Ferrand, France) every 10 minutes, 30 minutes before laser application. The same anesthesia and pupil dilation were performed before each laser procedure and each angiogram.

The following 532 Argon laser (Viridis, Quantel Medical; ClermontFerrand) parameters were used to induce a reproducible rupture of Bruch's membrane (observed as a "bubble formation" during the argon delivery): $150 \mathrm{~mW}, 100 \mu \mathrm{m}$ spot size, and $100 \mathrm{~ms}$ duration. To perform photocoagulation on the rat eye, a slit lamp delivery system was used, with the coverslip serving as a contact lens. Three insults were performed in the temporal retina of one eye in each rat.

At 14 days after photocoagulation, FA was performed to confirm the formation of CNV. For FA, sodium fluorescein (vol/vol in injectable water) was injected in the tail vein $(100 \mu \mathrm{L})$, and angiography was performed with a portable fundus camera (Kowa, Genesis, Tokyo, Japan) and black-and-white film (2400; Ilford, Paramus, NJ).

Performance of Stakel PDT in the Rat. Screening for occlusive parameters was performed, and the results of these experiments will be reported in a separated paper.

We present herein the experiments performed with the parameters determined to be occlusive for CNV in the rat: $5 \mathrm{mg} / \mathrm{kg}$ Stakel PDT, 100 $\mathrm{J} / \mathrm{cm}^{2} 753$-nm laser (600 mW/ $\mathrm{cm}^{2}, 166$ seconds), and DLI of 1 minute.

PDT was performed as described for the rabbit eye, except that laser burns were delivered using coverslips for fundus visualization and a laser spot size of $600 \mu \mathrm{m}$.
FIGURE 1. Pharmacokinetics of Stakel. Blood concentrations in rabbits receiving an intravenous bolus injection of WST-11.

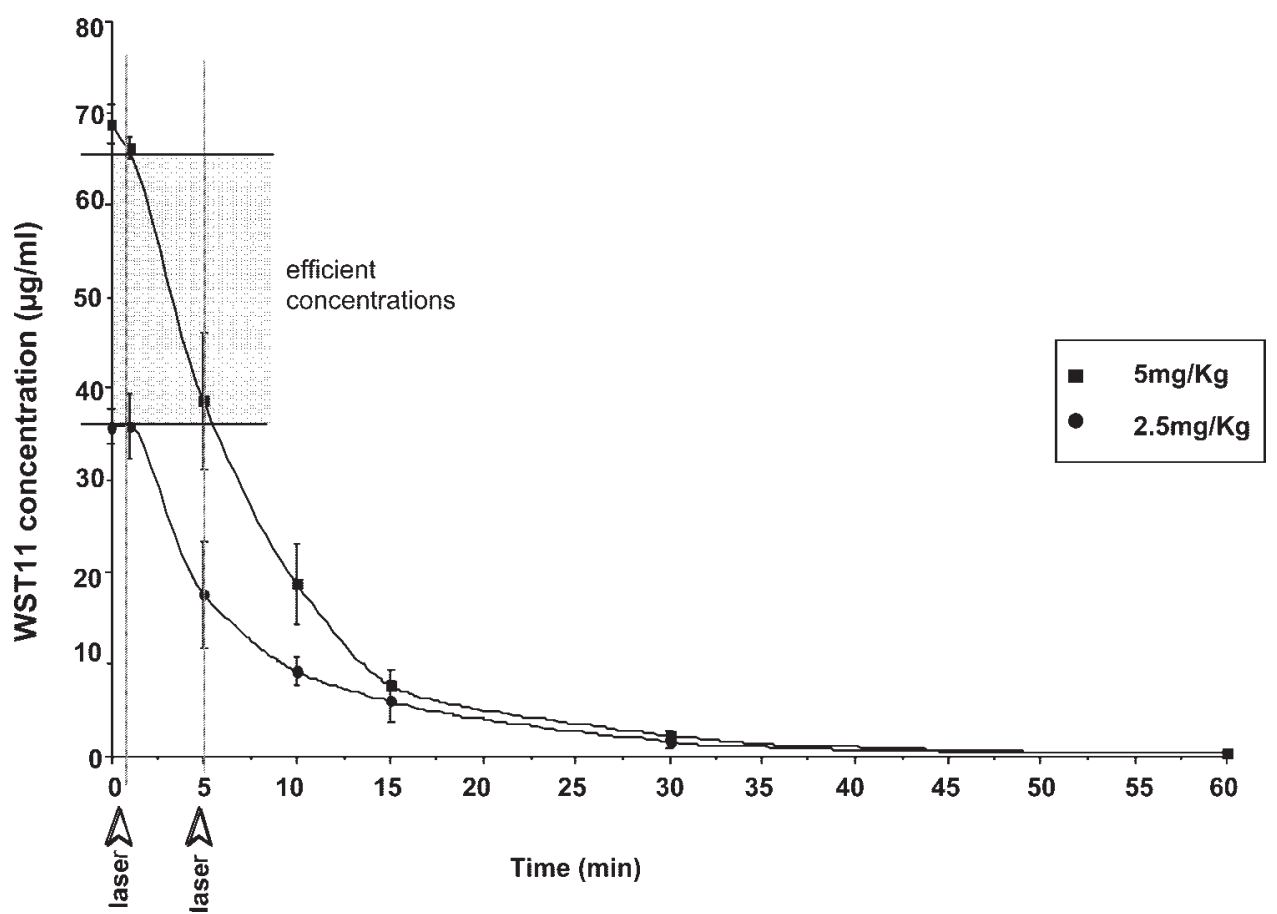


Evaluation of the Effect of Stakel PDT on Rat CNV. Four rats were treated with Stakel PDT. Four additional rats received the laser alone $\left(100 \mathrm{~J} / \mathrm{cm}^{2}\right)$ without injection of Stakel and were used as the control.

FA was performed 2 days before treatment and 2 and 8 days after treatment, for the evaluation of the efficacy and stability of vessel occlusion. A CNV was defined as closed after treatment if there was no leakage from the treated vascular membrane compared with its baseline pattern. Angiograms were graded by two masked readers.

Two PDT-treated and two control rats were killed 2 days after treatment, and their eyes were processed for analysis of semithin sections by using the same protocol as described for the rabbit retina.

\section{Results}

\section{Binding of WST-11 to Plasma Proteins}

The binding patterns of WST-11 to blood cells and plasma of rabbit and humans were very similar. Stakel did not show affinity binding to the blood cells, but showed strong binding affinity to the plasma proteins, with an $\mathrm{nKa}=95.9 \pm 27.8$ for the plasma and a binding percentage of $98.97 \%$. The percentage of Stakel binding to plasma proteins increased linearly with increased concentration of the drug within the solution. When Stakel was incubated with a reconstituted whole blood (both plasma and cells), the binding pattern was similar to that observed with plasma alone ( $>98 \%$ of binding to proteins). Furthermore, when a solution of Stakel bound to plasma proteins was incubated with the blood cell fraction (to mimic reconstituted blood with Stakel already bound to the plasma proteins), no release of the bound Stakel from the plasma and secondary binding to the blood cells occurred. WST-11 therefore has a strong binding affinity to plasma proteins without any significant binding affinity to blood cells. A previous study has shown that WST-11, because of its negative charges, has a selective affinity to serum albumin. ${ }^{20}$

\section{WST-11 Pharmacokinetics}

One minute after intravenous injection of 2.5 or $5 \mathrm{mg} / \mathrm{kg}$, circulating blood Stakel concentrations were, on average, 36 and $66 \mu \mathrm{g} / \mathrm{mL}$, respectively. These levels declined to approximately $7 \mu \mathrm{g} / \mathrm{mL}$ at 15 minutes and to $0.40 \mu \mathrm{g} / \mathrm{mL}$ at 60 minutes after injection (Fig. 1).

\section{Stakel PDT}

Effect of Drug Injection Alone. The injected doses of 2.5 and $5.0 \mathrm{mg} / \mathrm{kg}$ WST-11without laser illumination did not induce any noticeable angiographic or histologic damage in the ocular tissues (not shown).

Effect of Laser Illumination Alone. Control illumination with the $753-\mathrm{nm}$ laser at fluence of either 25 or $50 \mathrm{~J} / \mathrm{cm}^{2}$ (without drug injection) did not result in any angiographic changes on days 2 and 8 after illumination. Histologic examination of these eyes showed a normal pattern without any observable pathologic change in the tissue.

Screening for Occlusive Parameters. Angiography at day 2 showed that when PDT was performed at a fluence of 50 $\mathrm{J} / \mathrm{cm}^{2}$, a Stakel dose of $5 \mathrm{mg} / \mathrm{kg}$, and a DLI of 1 minute, hypofluorescence was observed in the center of the five lesions, with a hyperfluorescent ring in the periphery (Figs. 2A, 2B). This pattern remained constant during all phases of the angiography. On day 8 after PDT, the persistence of hypofluorescence of the lesion center (compatible with an interpretation of stable occlusion of the choroid vessels at this site) was observed while the hyperfluorescence intensity of the surrounding ring decreased markedly (not shown). At 30 days after treatment, reperfusion of the occluded vessels occurred
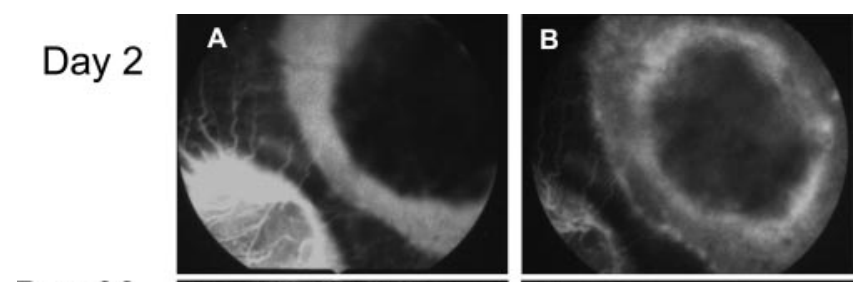

Day 30
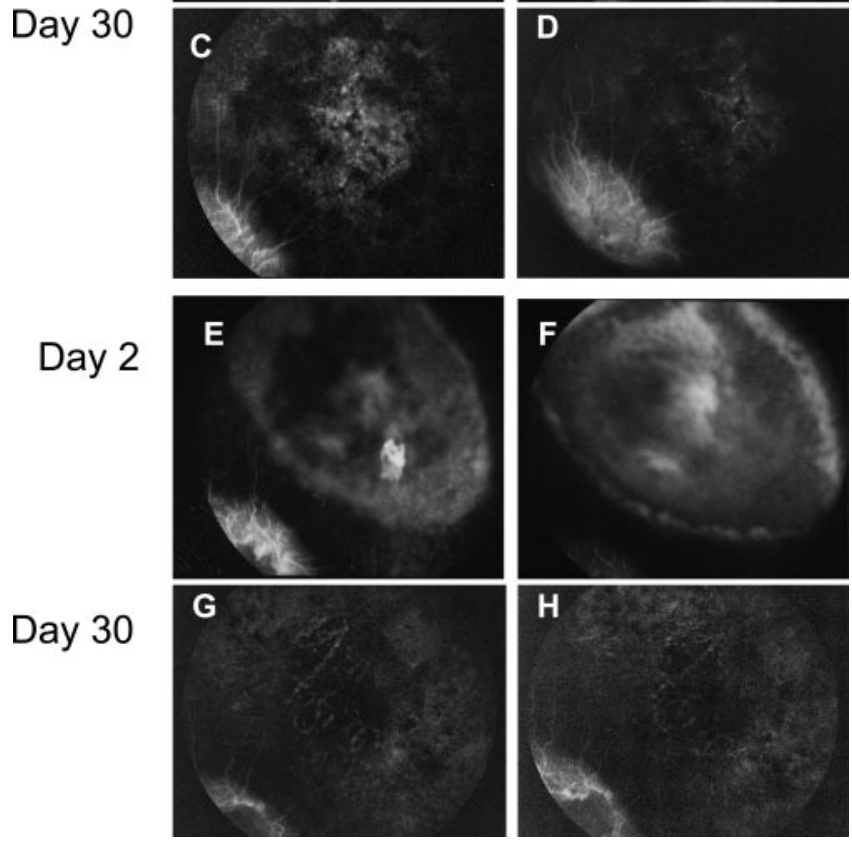

FIGURE 2. Fluorescein angiograms after Stakel PDT ( $5 \mathrm{mg} / \mathrm{kg}$, fluence of $50 \mathrm{~J} / \mathrm{cm}^{2}$, and DLI of 1 or 5 minutes). DLI 1 minute: FA performed on day 2 after PDT showed a hypofluorescence of the lesion center and a ring of hyperfluorescence around it during the early phase (A). The hyperfluorescence decreased during the late phase (B). Day 30: window effect was observed on the early (C) and late (D) phases of the angiography. DLI 5 minutes: FA performed on day 2 after PDT showed partial occlusion of the choriocapillaries in the illuminated spot and a patchy hyperfluorescence around it $(\mathbf{E}, \mathbf{F})$. On day 30 , a window effect was observed on the early $(\mathbf{G})$ and late $(\mathbf{H})$ phases of the angiography.

in all lesions, which also demonstrated angiographic pattern changes compatible with pigment alterations (Figs. 2C, 2D).

When the PDT parameters just described were used but the DLI increased to 5 minutes, whitening of the lesions was barely observed in the treated sites. On FA at day 2 after treatment, small patches of hyperfluorescence (leakage) were observed within the lesion site with partial vessel nonperfusion (Figs. 2E, 2F). On day 8 after treatment, FA showed a diffuse pattern of hypo- and hyperfluorescent spots, and on day 30, a patchy window effect resulting from RPE alterations was observed (Figs. 2G, 2H). Similar PDT parameters with a DLI of 10 or 15 minutes did not show any clinical or angiographic aspects of choroid vessel occlusion. In these eyes, FA performed on days 2 and 8 demonstrated angiographic patterns similar to those observed in non-PDT-treated, control eyes.

PDT performed at a laser fluence of $25 \mathrm{~J} / \mathrm{cm}^{2}$, a Stakel dose of $5 \mathrm{mg} / \mathrm{kg}$, and a DLI of 1 minute induced the appearance of a whitish lesion in all treatment sites immediately after treatment. Later, on day 2, FA demonstrated a hypofluorescence of the lesion center with a ring of mild hyperfluorescence around it in two of the five treated sites (not shown). No hypofluorescence was observed in the three other treatment sites. When the same laser fluence and drug dose were used, but the DLI was increased to 5,10 , or 15 minutes, the treated eyes dis- 

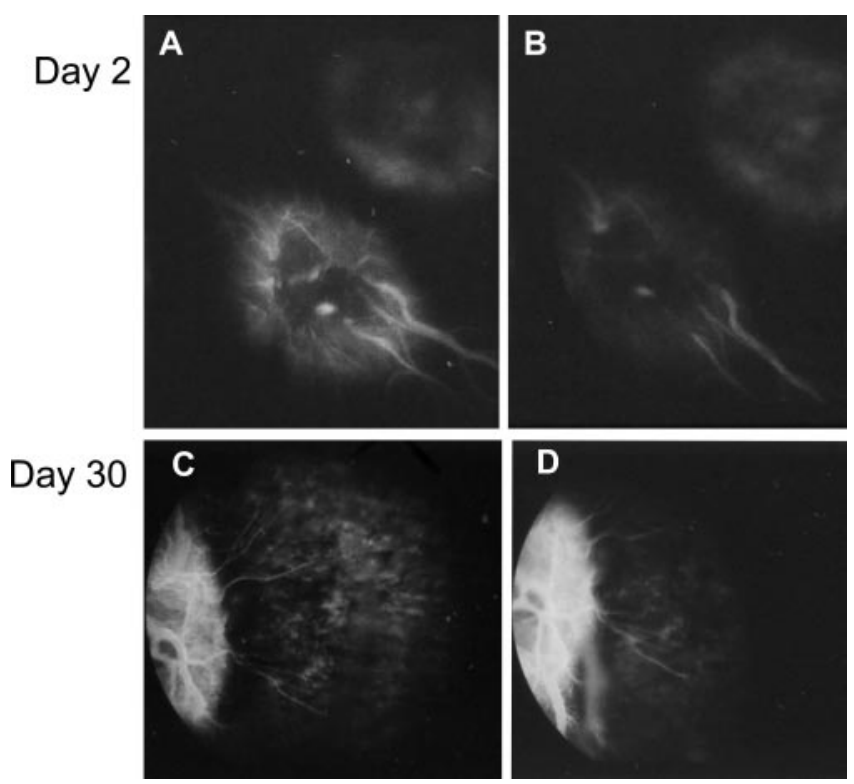

FIGURE 3. Fluorescein angiograms 2 and 30 days after Stakel PDT (2.5 $\mathrm{mg} / \mathrm{kg}$, fluence $50 \mathrm{~J} / \mathrm{cm}^{2}$, and 1 minute DLI). Day 2: early and late phases of the angiogram (A, B) showed partial choroidal occlusion, with hyperfluorescence around the illuminated spot. Day 30: a spotty window effect was observed in the early (C) and late (D) phases of the angiogram.

played an FA pattern similar to that observed in nontreated, control eyes.

PDT performed at a laser fluence of $50 \mathrm{~J} / \mathrm{cm}^{2}$, a Stakel dose of $2.5 \mathrm{mg} / \mathrm{kg}$, and a DLI of 1 minute induced a mild whitening of the treated spot in all five eyes, immediately after treatment. FA performed on days 2 and 8 after treatment, displayed a heterogeneous pattern of hypo- and hyperfluorescence of the lesion in three of the five eyes (Figs. 3A, 3B). This FA pattern is compatible with small patchy occlusions of the choroid vessels. When the DLI was increased to 5 minutes, FA on days 2 and 8 did not demonstrate any choroidal vessel occlusion (not shown). When occlusion of choroidal vessels occurred, changes in pigmentation were clinically visible on day 8 after treatment and persisted on day 30. These pigment alterations are most probably the result of ischemia and disruption of the RPE layer's integrity (Figs. 3C, 3D).

Table 1 summarizes the efficacy of choroidal occlusion with the use of the different laser parameters and WST-11 doses. As shown, reducing by half either the energy or WST-11 dose, but keeping a 1-minute DLI reduced the occlusion efficacy by nearly $50 \%$. On the other hand, increasing the DLI from 1 to 5 minutes reduced the occlusion efficacy by $80 \%$. No occlusion was observed when DLI was $\leq 10$ minutes. This demonstrates that, due to its very rapid clearance, WST-11 efficacy depends highly on the time elapsing between the drug infusion and the initiation of laser illumination (DLI).

TABLE 1. Occlusion Rates on Day 2 after WST-11 with Different PDT Parameters

\begin{tabular}{cccc}
\hline & \multicolumn{3}{c}{ DLI } \\
\cline { 2 - 4 } $\begin{array}{c}\text { WST-11 (mg/kg)/ } \\
\text { Laser Fluence }\left(\mathbf{J} / \mathbf{c m}^{2}\right)\end{array}$ & $\mathbf{1}$ min & $\mathbf{5}$ min & $\mathbf{2 1 0} \mathbf{~ m i n}$ \\
\hline $5 / 50$ & 100 & 20 & 0 \\
$5 / 25$ & 40 & 0 & 0 \\
$2.5 / 50$ & 60 (partial) & 0 & 0 \\
\hline
\end{tabular}

Data are expressed as the percentage of vessels occluded.
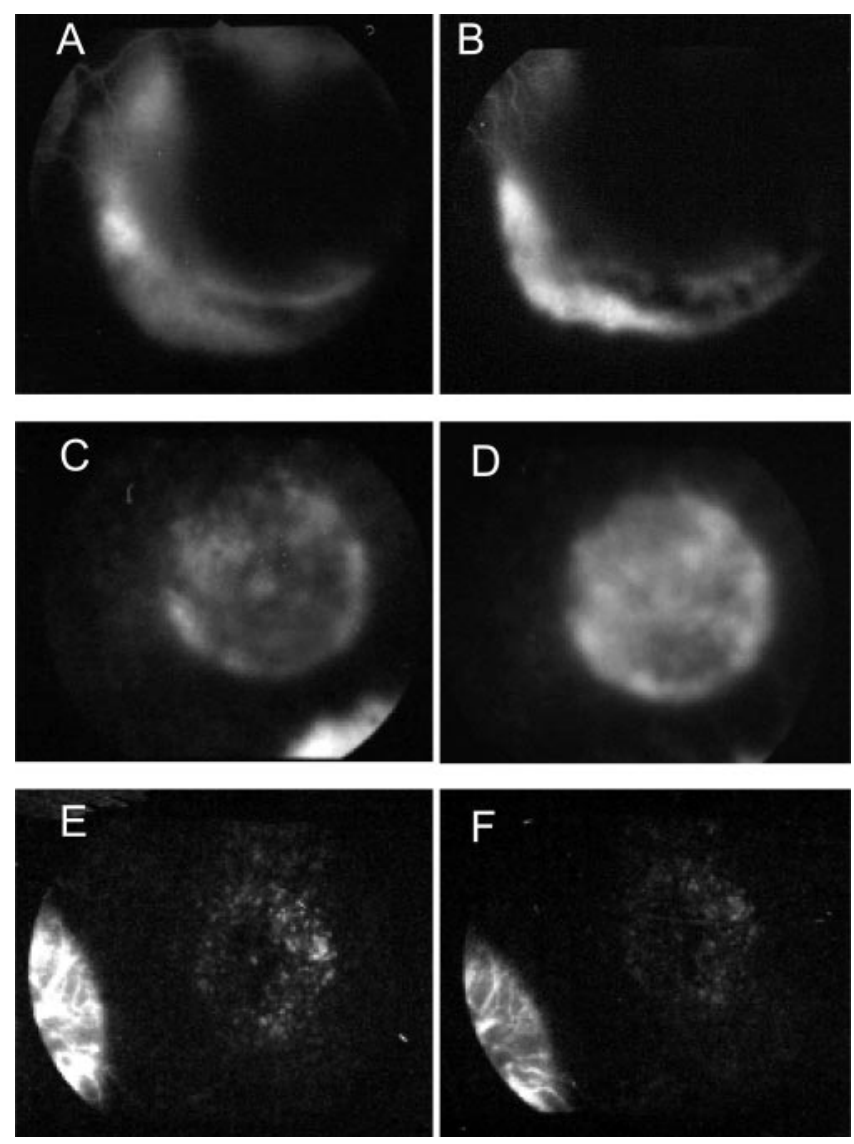

FIGURE 4. Fluorescein angiograms 2 days after verteporfin PDT. With $6 \mathrm{mg} / \mathrm{m}^{2}, 50 \mathrm{~J} / \mathrm{cm}^{2}$ fluence, and 5-minute DLI: representative FA of a treated eye showing hypofluorescence of the lesion surrounded by a hyperfluorescent ring during the early (A) and late (B) phases. With 3 $\mathrm{mg} / \mathrm{m}^{2}, 10 \mathrm{~J} / \mathrm{cm}^{2}$ fluence, and 5-minute DLI: representative FA showing no evidence of choroidal occlusion in the early (C) and late angiogram phases (D). Day 30: window effect due to RPE changes was observed on the early (E) and (F) late phases of the angiogram.

\section{Verteporfin PDT}

PDT performed at a fluence of $50 \mathrm{~J} / \mathrm{cm}^{2}$, a verteporfin dose of $6 \mathrm{mg} / \mathrm{m}^{2}$, and a DLI of 5 minutes induced the formation of a grayish lesion at the site of illumination in all nine treated eyes, immediately after treatment. FA performed on days 2 and 8 demonstrated a pattern compatible with choroidal vessel occlusion within the lesion (hypofluorescent lesion surrounded by a peripheral hyperfluorescent ring) only in two (22\%) of the nine treated eyes (Figs. 4A, 4B). Increasing fluence to 100 $\mathrm{J} / \mathrm{cm}^{2}$ and the verteporfin dose to $12 \mathrm{mg} / \mathrm{m}^{2}$ induced the appearance of a whitish lesion in all nine treated eyes. FA performed on days 2 and 8 demonstrated an occlusive pattern in eight (89\%) of the nine treated eyes. FA performed on day 30 showed reperfusion of vessels within these lesions.

Treatment with a fluence of $10 \mathrm{~J} / \mathrm{cm}^{2}$, a verteporfin dose of $3 \mathrm{mg} / \mathrm{m}^{2}(0.2 \mathrm{mg} / \mathrm{kg})$, and a DLI of 5 minutes did not induce any significant clinical changes. FA performed on days 2 and 8 showed a diffuse window effect of hyperfluorescence in all nine eyes without any evidence of choroidal vessel occlusion (Fig. 4C). Late angiography phases showed diffuse leakage (Fig. $4 \mathrm{D})$. In most of the treated eyes, pigmentation changes occurred and were already visible on day 8 after PDT. On day 30, only window effects due to RPE alterations were observed (Figs. 4E, 4F).

Table 2 summarizes the FA occlusion findings with the different parameters. 
TABLE 2. Occlusion Rates on Day 2 after Verteporfin PDT with Different Parameters

\begin{tabular}{cc}
\hline $\begin{array}{c}\text { Vertepofin }\left(\mathbf{m g} / \mathbf{m}^{2}\right) / \\
\text { Laser Fluence }\left(\mathbf{J} / \mathbf{c m}^{2}\right), \text { DLI } \mathbf{~} \text { min }\end{array}$ & Rate $(\%)$ \\
\hline $12 / 100$ & 89 \\
$6 / 50$ & 22 \\
$3 / 10$ & 0 \\
\hline
\end{tabular}

\section{Histology}

WST-11 PDT. Two hours after occlusive Stakel PDT (fluence $50 \mathrm{~J} / \mathrm{cm}^{2}, 5 \mathrm{mg} / \mathrm{kg}$, and a DLI of 1 minute), dilatation of the choroid vessels was observed. RPE cells were relatively well preserved despite some vacuolization (Figs. 5A, 5B). The ONL anatomy was without any noticeable pathologic changes (Fig. 5A). TEM showed that, at this time point, Bruch's membrane and the RPE cells were intact (Figs. 5C, 5D). Some of the endothelial cells choriocapillaries were markedly altered (Fig. 5C). In the vessel lumens, monocytes and hemolyzed red blood cells were seen (Fig. 5D).

On day 2 after treatment, eyes treated with PDT occlusive parameters (fluence $50 \mathrm{~J} / \mathrm{cm}^{2}, 5 \mathrm{mg} / \mathrm{kg}$ Stakel, and a DLI of 1 minute) demonstrated histologic grade- 3 and -4 lesions (Table 3 , Fig. 6A). On day 30 after treatment, grade- 4 and -5 lesions were observed with these Stakel PDT occlusive parameters (Table 3, Fig. 6B).

With the use of nonocclusive Stakel PDT parameters (25 $\mathrm{J} / \mathrm{cm}^{2}, 5 \mathrm{mg} / \mathrm{kg}, 10$-minute DLI), grade-1 histologic changes were observed on day 2 after treatment (Table 3, Fig. 6C). On day 30 after treatment, grade- 0 or -1 changes were observed (Table 3, Fig. 6D).

Verteporfin PDT. Two hours after occlusive verteporfin PDT $\left(100 \mathrm{~J} / \mathrm{cm}^{2}, 12 \mathrm{mg} / \mathrm{m}^{2}\right.$, DLI of 5 minutes), exudates and cell debris were observed between the RPE layer and the neuroretina overlying the treated area (Fig. 7A). RPE cells were damaged, and their cytoplasmic membranes were affected (Fig. 7B). TEM examination showed fragmentation of the endothelial cell nuclei and fibrin deposits within and outside the choriocapillaries (Figs. 7C, 7D).

On day 2 after treatment, the histologic damage grade was 4 or 5 in all treated eyes (Table 4, Fig. 8A). On day 30, all treated eyes demonstrated grade-5 histologic damage (Table 4 , Fig. 8B).

In verteporfin PDT, with a fluence of $50 \mathrm{~J} / \mathrm{cm}^{2}$, a $6-\mathrm{mg} / \mathrm{m}^{2}$ dose, and a DLI of 5 minutes, on day 2 after treatment, the retina and choroid structural damage were of grade 3 and 4 (Table 4). The RPE layer was altered, with vacuolization, swelling, and pigment dispersion (Fig. 8C). On day 30, disorganization of the retinal layers and RPE layer was observed, along with the presence of melanophages (Fig. 8D).
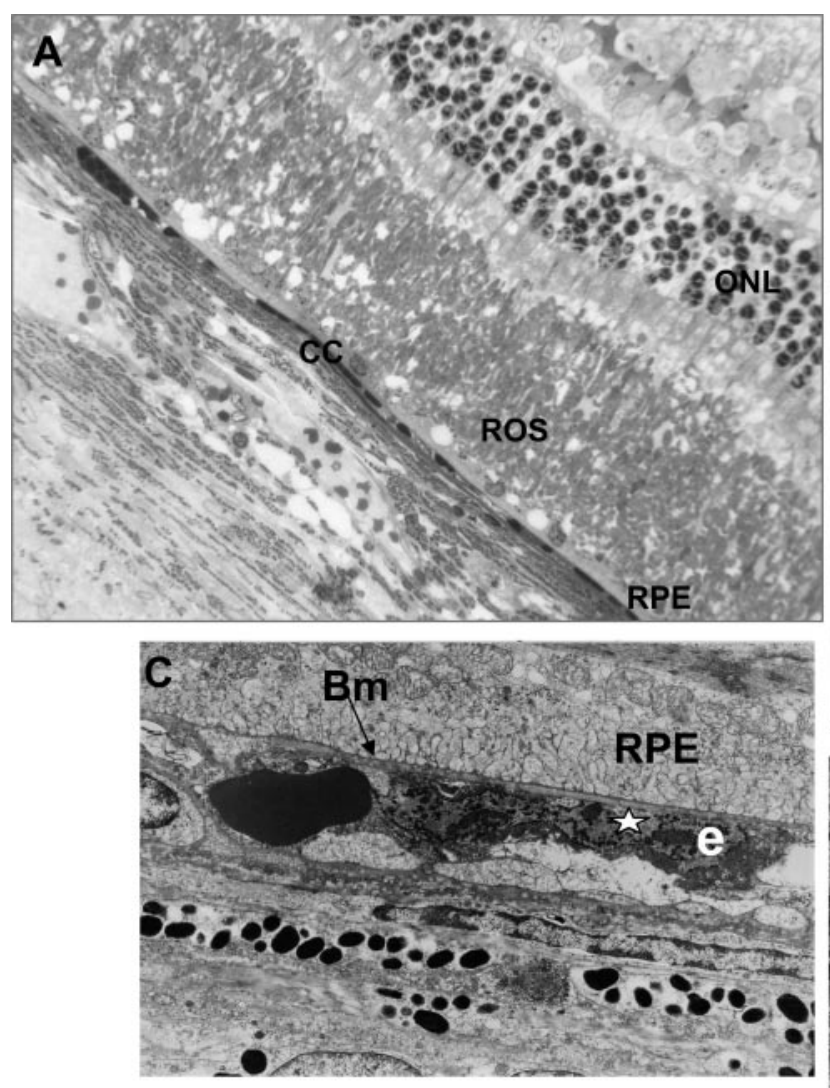
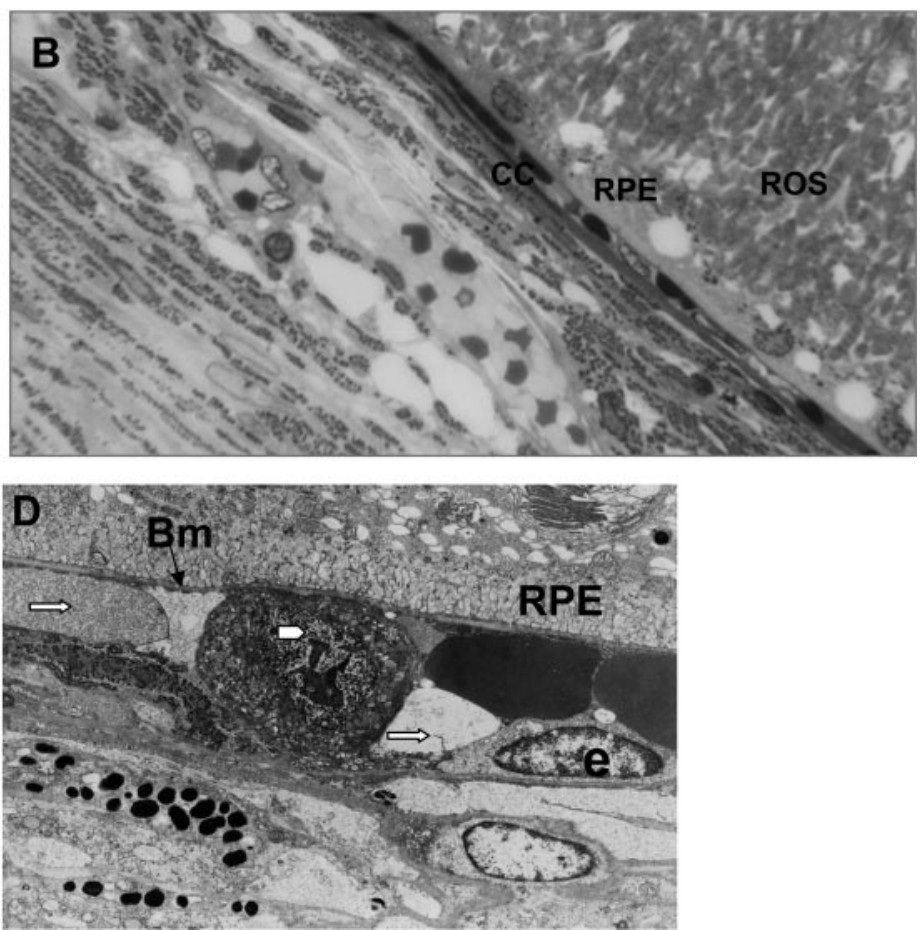

Figure 5. Semithin sections and TEM of the lesion center 2 hours after occlusive Stakel PDT (fluence $50 \mathrm{~J} / \mathrm{cm}^{2}, 5 \mathrm{mg} / \mathrm{kg}$, and a DLI of $1 \mathrm{minute}$ ). Stasis and dilatation of choroidal vessels with relatively well-preserved RPE cells and retina are observed (A, B). (C, D) TEM showed hemolysis of the red blood cells within the choriocapillary lumen (D, white arrows) and disrupted monocytes (D, white arrowhead). (C) Bruch's membrane (Bm) was intact, harboring easily identified RPE cells (RPE). Some of the choriocapillary endothelial cells were markedly altered demonstrating condensed chromatin (C, star). ONL, outer nuclear layer; ROS, rod outer segments; CC: choriocapillary; e, endothelial cells. 
TABLE 3. Histologic Damage Grade on Days 2 and 30 after WST-11 PDT with Occlusive and Nonocclusive Parameters

\begin{tabular}{lcccccc}
\hline WST-11 (753 nm) & Grade 0 & Grade 1 & Grade 2 & Grade 3 & Grade 4 & Grade 5 \\
\hline Day 2 & & & & & & \\
$50 \mathrm{~J} / \mathrm{cm}^{2}, 5 \mathrm{mg} / \mathrm{kg}$, DLI 1 min & $0 / 3$ & $0 / 3$ & $0 / 3$ & $2 / 3$ & $1 / 3$ & $0 / 3$ \\
$25 \mathrm{~J} / \mathrm{cm}^{2}, 5 \mathrm{mg} / \mathrm{kg}$, DLI $10 \mathrm{~min}$ & $0 / 3$ & $3 / 3$ & $0 / 3$ & $0 / 3$ & $0 / 3$ & $0 / 3$ \\
Day 30 & & & & & & \\
$50 \mathrm{~J} / \mathrm{cm}^{2}, 5 \mathrm{mg} / \mathrm{kg}$, DLI $1 \mathrm{~min}$ & $0 / 3$ & $0 / 3$ & $0 / 3$ & $0 / 3$ & $2 / 3$ & $1 / 3$ \\
$25 \mathrm{~J} / \mathrm{cm}^{2}, 5 \mathrm{mg} / \mathrm{kg}$, DLI $10 \mathrm{~min}$ & $2 / 3$ & $1 / 3$ & $0 / 3$ & $0 / 3$ & $0 / 3$ & $0 / 3$ \\
\hline
\end{tabular}

These changes are compatible with grade- 4 and -5 histologic changes (Table 4 ).

In all eyes treated with $10 \mathrm{~J} / \mathrm{cm}^{2}$, verteporfin $3 \mathrm{mg} / \mathrm{m}^{2}$, and DLI of 5 minutes, no angiographic or histologic findings of choroidal vascular occlusion were detected. Histology performed on day 2, however, showed pyknotic nuclei in the ONL, alteration of the photoreceptors outer segments, RPE cell vacuolization, swelling, and loss of the apical pigmentation, along with subretinal exudation (Fig. 9A). On day 30, the exudation had resolved, but the ONL cell density was further reduced. The marked loss of outer segments and RPE damage was associated with infiltration of melanophages at the RPE level (Figs. 9B, 9C). These structural alterations are compatible with grade- 3 and -4 pathologic changes.
WST-11 $5 \mathrm{mg} / \mathrm{Kg}, 50 \mathrm{~J} / \mathrm{cm}^{2}$, DLI $1 \mathrm{~min}$

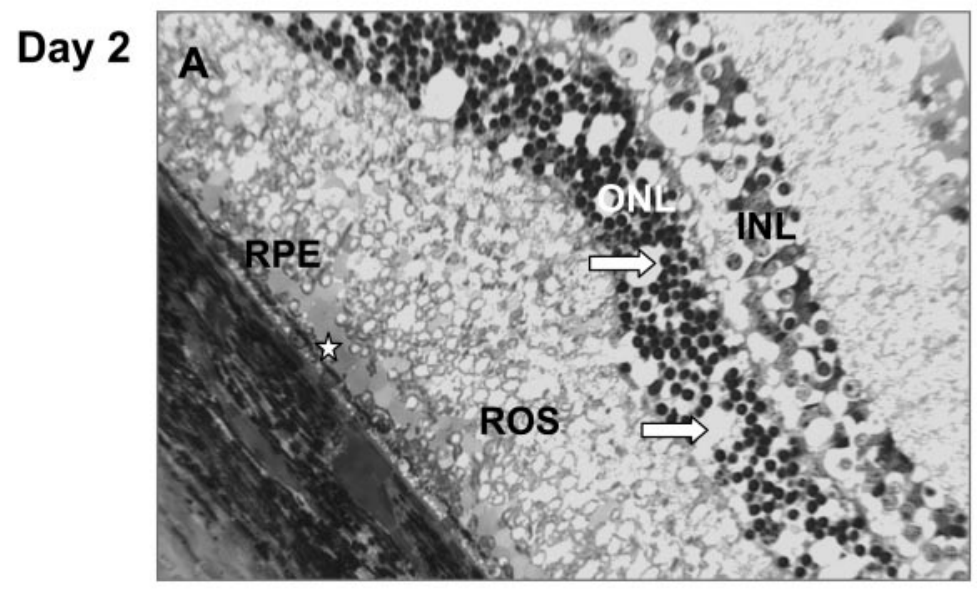

\section{Day 30}

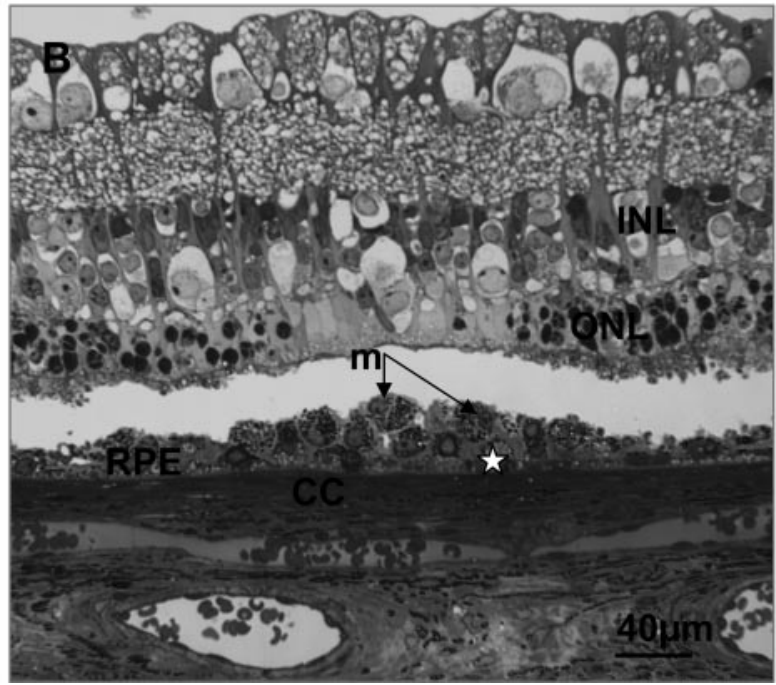

\section{WST-11 $5 \mathrm{mg} / \mathrm{Kg}, 25 \mathrm{~J} / \mathrm{cm}^{2}$, DLI 10min}
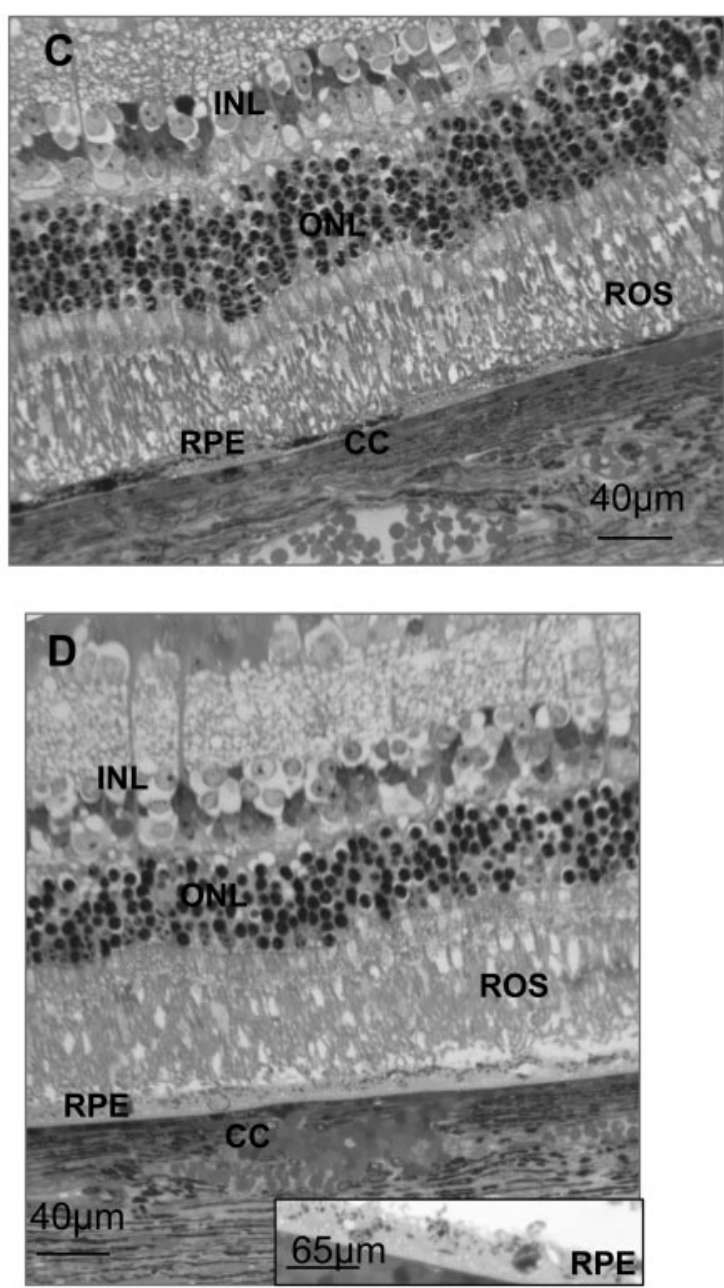

FiguRE 6. Semithin sections of the lesion center 2 and 30 days after Stakel PDT with occlusive parameters (fluence $50 \mathrm{~J} / \mathrm{cm}^{2}, 2.5 \mathrm{mg} / \mathrm{kg}$, and a DLI of 1 minute) Day 2: (A) mild subretinal exudation, disruption of the RPE cells (star), total disorganization of the ROS, pyknosis, and loss of nuclei in the ONL (arrows). Day 30: (B) proliferation of undifferentiated RPE cells (star), presence of melanophages (m), total loss of ROS, and marked loss of the ONL nuclei. (C, D) With nonocclusive parameters: fluence $50 \mathrm{~J} / \mathrm{cm}^{2}, 5 \mathrm{mg} / \mathrm{kg}$, and a DLI of 10 minutes. Day 2: (C) only mild pigment dispersion changes in the RPE cells. Day 30: (D) essentially normal retinal structures are observed but for mild RPE pigment dispersion (inset). 

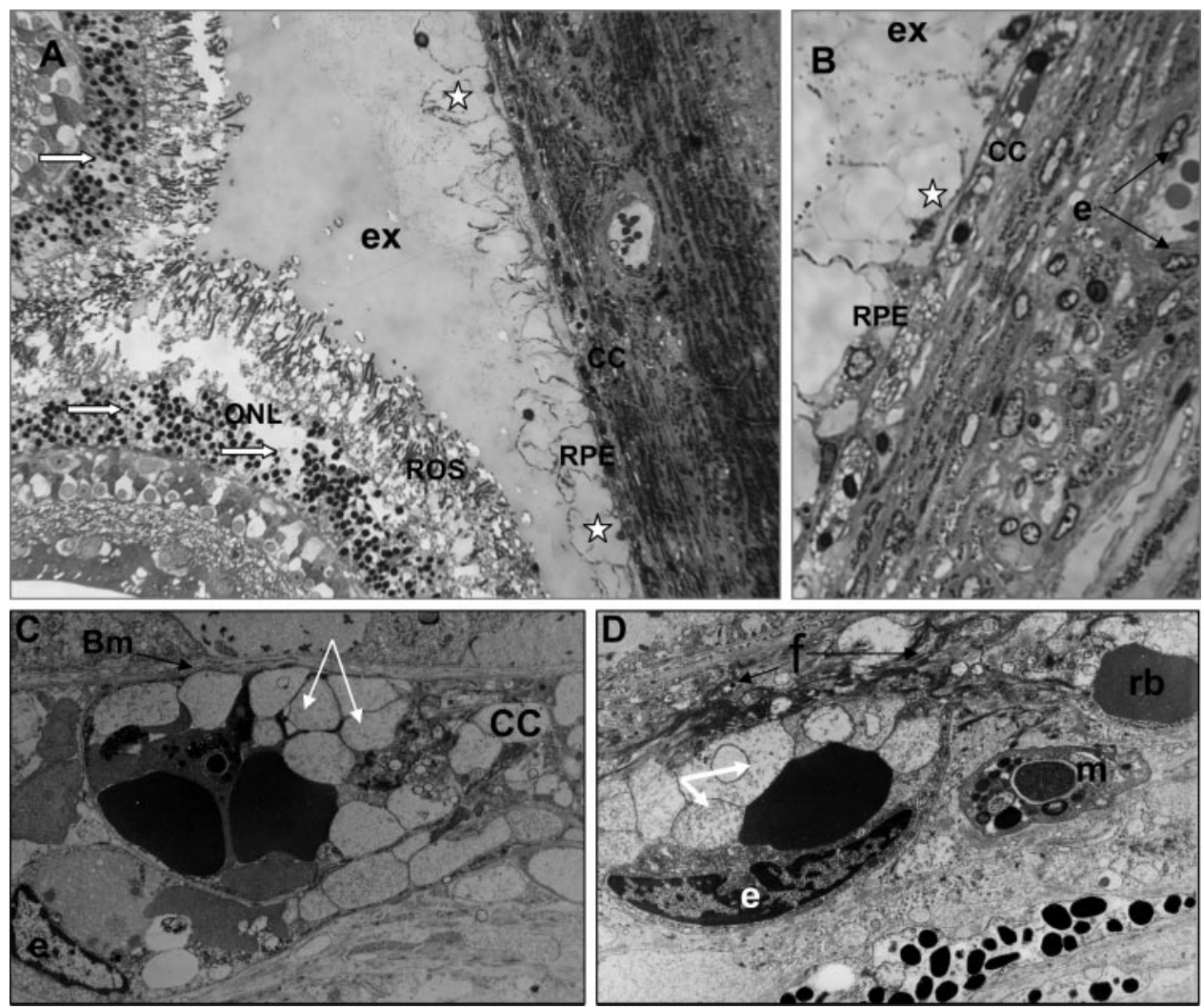

Figure 7. Semithin sections and TEM of the lesion center 2 hours after occlusive verteporfin PDT (100 $\mathrm{J} / \mathrm{cm}^{2}, 12 \mathrm{mg} / \mathrm{m}^{2}$, and DLI of $5 \mathrm{~min}$ utes). (A) Subretinal exudates and cell debris, disorganization of ROS, and marked loss and pyknosis of ONL nuclei (arrows) were observed. RPE cells were disrupted, expelling their contents (A, B, white stars). TEM showed fragmentation of the choriocapillary endothelial cell nuclei (E), hemolysis of red blood cells (C, D, white arrows), and distribution of fibrin deposits within and outside the choriocapillaries $(\mathbf{F}, \mathbf{D})$.

\section{Selective CNV Closure in the Rat Eye Using Stakel PDT}

As shown by the FA leakage in the late phases of the angiograms, 14 days after argon laser photocoagulation, CNV was induced in the rat eyes (Figs. 10A, 10B).

Stakel-PDT induced CNV closure at 2 and 8 days in $100 \%$ of the treated lesions. Figure $10 \mathrm{~B}$ shows a representative case of abnormal vessel occlusion 2 and 8 days after PDT, as demonstrated by the absence of leakage in the CNV lesions during the late phases of the angiograms. The retinal vessels were patent; none were occluded when these parameters are used. In the group of rats treated with laser alone (no drug infused), no vascular changes or occlusion of the $\mathrm{CNV}$ were observed on days 2 and 8 after illumination (Fig. 10A).

Semithin-section histologic analysis of the retina confirmed that a selective occlusion of the CNV occurred 2 days after Stakel PDT (Fig. 11B). High magnification (Fig. 11b) showed thrombosis in the CNV of treated rat eyes, but not in the CNV control eyes (Fig. 11a). Of note, no detachment of the retina was observed, and RPE cells in the illuminated area on the border of the CNV (Fig. 11b) were well preserved.

\section{Discussion}

PDT has the potential to induce permanent closure of CNV by its direct influence on vascular components ${ }^{25}$ and apoptosis of endothelial cells. ${ }^{26}$ However, apparently, PDT does not slow down the ongoing proangiogenic processes taking place in AMD (and may even enhance them) by increasing the release of proangiogenic factors. ${ }^{27,28}$ Preclinical verteporfin PDT studies have shown that, even with nonocclusive parameters, RPE lesions, photoreceptor disruption, and cell pyknosis occur. ${ }^{22}$ Studies conducted in primates have shown that the collateral damage caused by verteporfin PDT is still present after a long follow upperiod. ${ }^{9}$ Human clinical studies have demonstrated constant early subretinal and intraretinal fluid accumulation, suggesting RPE barrier disruption. ${ }^{10}$ These observations indicate that verteporfin diffuses to the RPE and retina, causing significant damage. ${ }^{22,29}$ The tissue collateral damage induced by the presently available lipophilic photosensitizer may explain, at least in part, the reduced beneficial effect of PDT when compared with antiangiogenic compounds.

TABLE 4. Histologic Damage Grade on Days 2 and 30 after Verteporfin PDT

\begin{tabular}{lcccccc}
\hline Verteporfin $(689 \mathbf{~ n m})$ & Grade 0 & Grade 1 & Grade 2 & Grade 3 & Grade 4 & Grade 5 \\
\hline Day 2 & & & & & & \\
$10 \mathrm{~J} / \mathrm{cm}^{2}, 3 \mathrm{mg} / \mathrm{m}^{2}$ & $0 / 3$ & $0 / 3$ & $0 / 3$ & $2 / 3$ & $1 / 3$ & $0 / 3$ \\
$50 \mathrm{~J} / \mathrm{cm}^{2}, 6 \mathrm{mg} / \mathrm{m}^{2}$ & $0 / 3$ & $0 / 3$ & $0 / 3$ & $1 / 3$ & $2 / 3$ & $0 / 3$ \\
$\quad 100 \mathrm{~J} / \mathrm{cm}^{2}, 12 \mathrm{mg} / \mathrm{m}^{2}$ & $0 / 3$ & $0 / 3$ & $0 / 3$ & $0 / 3$ & $2 / 3$ & $1 / 3$ \\
Day 30 & & $0 / 3$ & $0 / 3$ & $2 / 3$ & $1 / 3$ & $0 / 3$ \\
$10 \mathrm{~J} / \mathrm{cm}^{2}, 3 \mathrm{mg} / \mathrm{m}^{2}$ & $0 / 3$ & $0 / 3$ & $0 / 3$ & $0 / 3$ & $0 / 3$ & $3 / 3$ \\
$50 \mathrm{~J} / \mathrm{cm}^{2}, 6 \mathrm{mg} / \mathrm{m}^{2}$ & $0 / 3$ & $0 / 3$ & $0 / 3$ & $0 / 3$ & $1 / 3$ & $2 / 3$ \\
$100 \mathrm{~J} / \mathrm{cm}^{2}, 12 \mathrm{mg} / \mathrm{m}^{2}$ & $0 / 3$ & & &
\end{tabular}


Verteporfin $12 \mathrm{mg} / \mathrm{m}^{2}, 100 \mathrm{~J} / \mathrm{cm}^{2}$
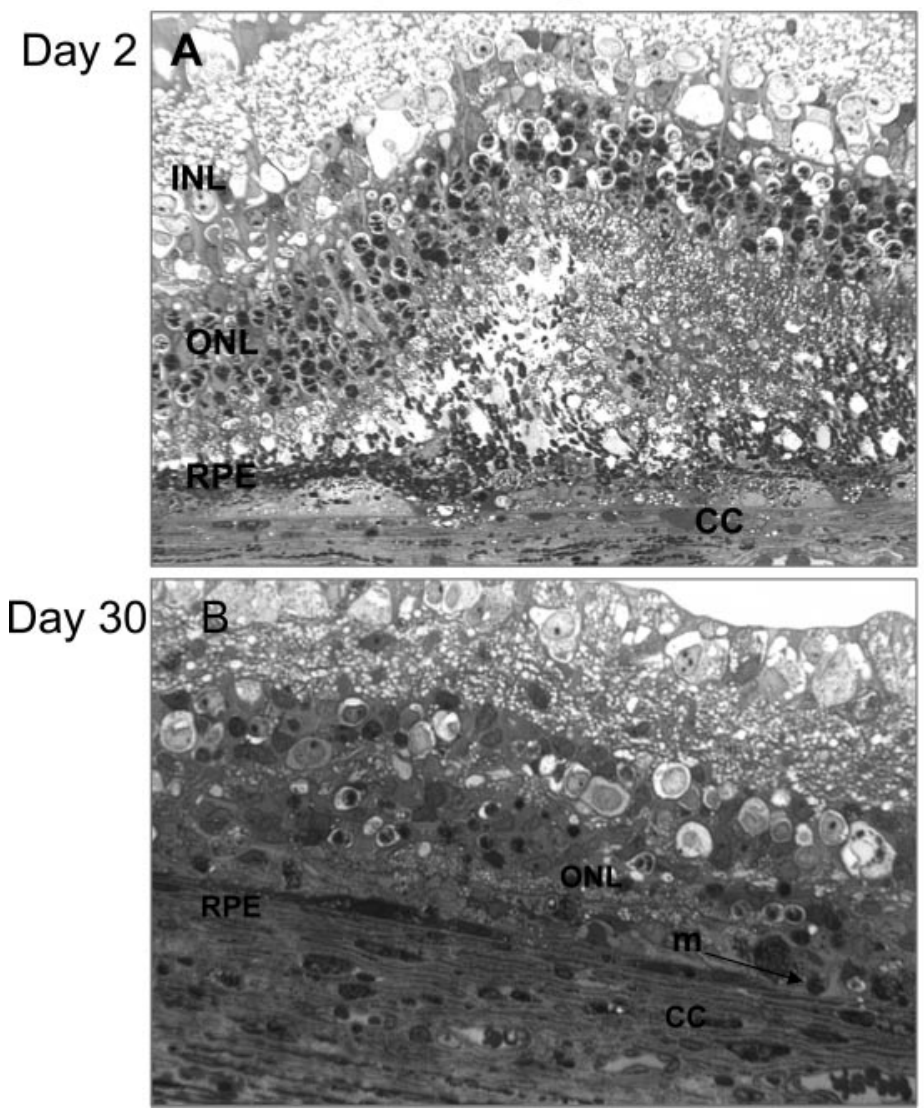

Verteporfin $6 \mathrm{mg} / \mathrm{m}^{2}, 50 \mathrm{~J} / \mathrm{cm}^{2}$
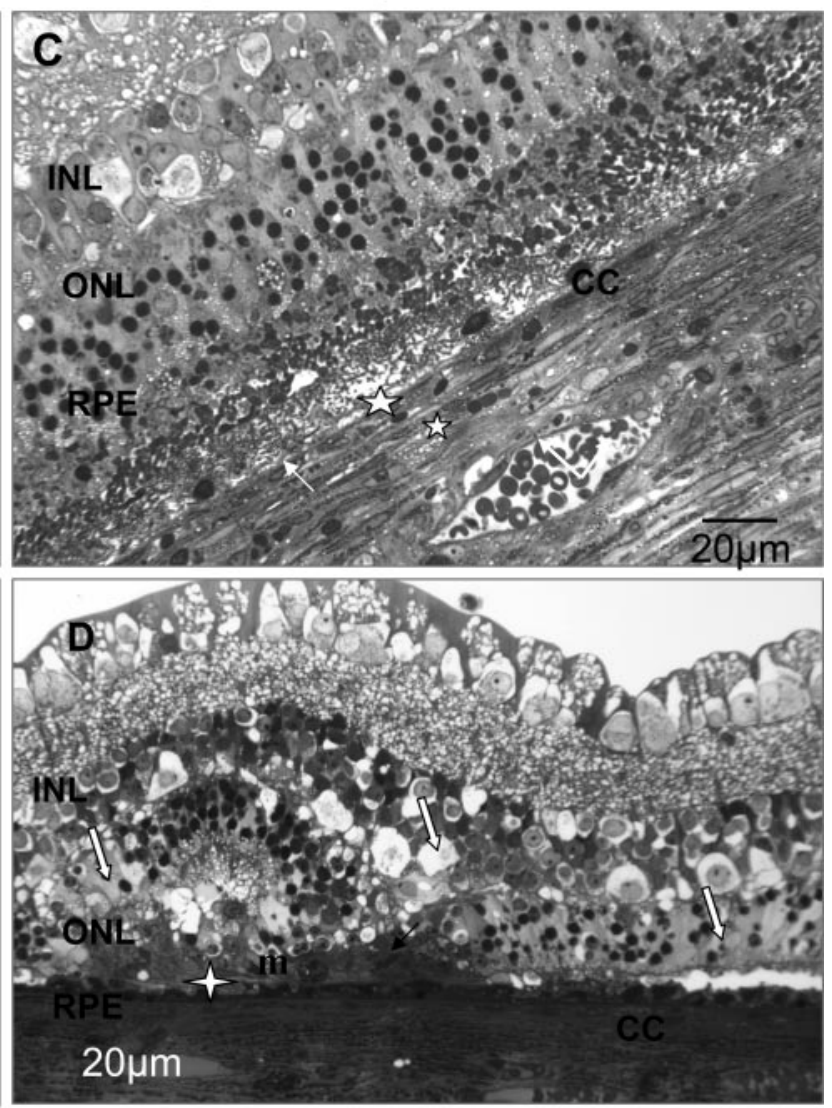

FIGURE 8. Semithin sections of the lesion center 2 and 30 days after verteporfin PDT. With occlusive parameters: fluence $100 \mathrm{~J} / \mathrm{cm}^{2}, 12 \mathrm{mg} / \mathrm{m}^{2}$, and DLI of 5 minutes. (A) Day 2: occlusion of the choriocapillary and some of the larger choroidal vessels were detected. Severe RPE damage (star), disorganization of ROS, ONL marked pyknosis, and nuclei loss (arrows) were also observed. (B) Day 30: total disorganization of the choroid and choriocapillaries in the outer and inner retina were observed. With nonocclusive parameters: fluence $50 \mathrm{~J} / \mathrm{cm}^{2}, 6 \mathrm{mg} / \mathrm{m}^{2}$, and DLI of $5 \mathrm{minutes}$. (C) Day 2: patchy RPE cells loss (stars), subretinal exudation, and structural disruption of the outer retina along with occlusion of the choriocapillaries (arrows). (D) Day 30: disorganization of the retinal layers, loss of nuclei in the ONL (white arrows), proliferation of the RPE cells (D, star), epithelioid proliferation (black arrow), and scattered melanophages (m).

At present, it is becoming evident that PDT has to be more $\mathrm{CNV}$-specific and cause less collateral tissue damage if higher therapeutic benefits are to be achieved.

After the development of effective anti-VEGF strategies, this therapeutic modality has become the first choice for wet AMD. However, although anti-VEGF therapies have a clear and rapid effect on subretinal fluid elimination, they do not destroy or close pre-existing neovessels. Therefore, the maintenance of VEGF blockade with repeated intraocular injections is required. ${ }^{30-33}$ Taking into consideration the present state of the art, a selected and safe occlusion of the abnormal vessels by PDT combined with an (or multiple) anti-VEGF strategy may yield the highest therapeutic benefits. This line of thought has led to the thorough evaluation of several photosensitizers. ${ }^{18,34-38}$ Most of these, however, have shown constant collateral RPE and photoreceptor damage. Because of its pharmacodynamic characteristics and high potential binding to albumin, the WST-11 photosensitizer (Stakel; Steba Biotech) appeared to be most promising for PDT purposes.

In the present study, we evaluated and compared the collateral damage induced by WST-11 and verteporfin PDT in the normal rabbit eye. PDT treatment with the two photosensitizers was performed with high occlusive parameters or with subthreshold, nonocclusive parameters. Furthermore, the selective effects of Stakel PDT on CNV induced in the rat eye were also analyzed.
In the normal rabbit eyes, 2 hours after application of Stakel PDT occlusive parameters, structural alterations were confined to the choriocapillaries. Blood stasis, hemolysis of red blood cells within the vessel lumens, and endothelial cell nuclear disruption were seen. However, at this stage, no blood clot formation or capillary occlusion was observed. These effects, which remained confined to the choriocapillaries, are compatible with those detected during the generation of reactive oxygen species. ${ }^{39}$ In verteporfin PDT-treated eyes, apart from the intravascular changes similar to those observed after Stakel PDT, fibrin deposits collected within and outside of the choroid vessels, and extensive exudation between the RPE cell layer and the neuroretina was induced. The localized intravascular effects of Stakel derive most probably from the fact that it has a very short half-life and remains confined to the blood vessel lumen during the DLI period (it is water soluble, binds to albumin, and is rapidly cleared from the circulation).

Two days after Stakel PDT, occlusion of the choriocapillaries within the treated area was observed. At this time point, damage to the RPE cells and the outer and inner retinal layers was detected, resulting from the occlusion of the choriocapillaries and some of the larger choroidal vessels.

Use of Stakel nonocclusive PDT parameters at 2 days did not cause any significant alteration in the retina overlying the illuminated spot. Thus, when no occlusion of the choroid and choriocapillaries was induced, the retina was not affected. 

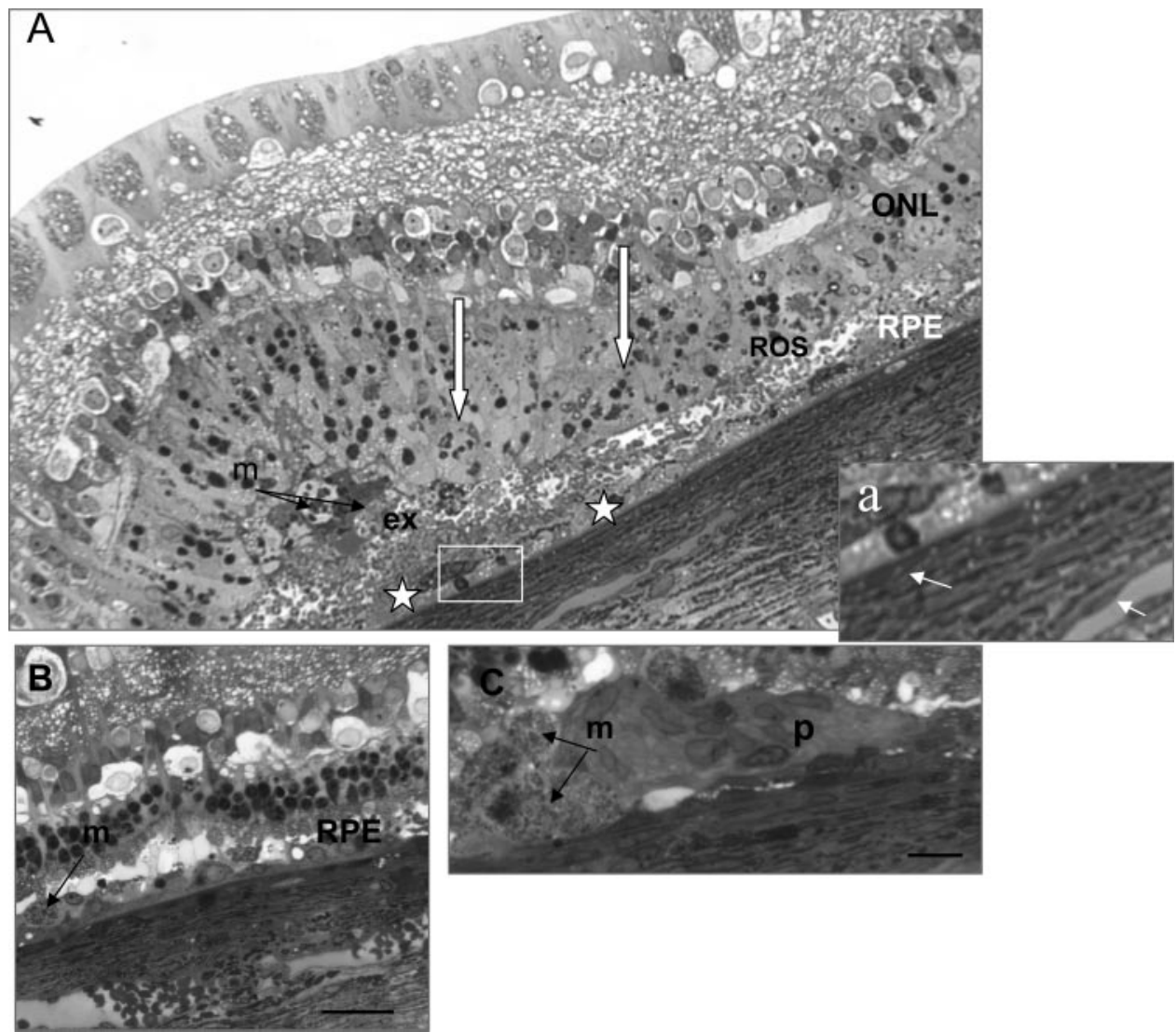

Figure 9. Semithin sections of the lesion center 2 and 30 days after verteporfin PDT with nonocclusive parameters $\left(3 \mathrm{mg} / \mathrm{m}^{2}\right.$, fluence 10 $\mathrm{J} / \mathrm{cm}^{2}$, and 5 minutes DLI). (A) Day 2 : alteration of the photoreceptor outer segments and the ONL with numerous pyknotic nuclei (white arrows), RPE cell vacuolization, swelling, and loss of pigmentation (stars). Choriocapillary endothelial cells are easily identified (a, short white arrows). Day 30: reduction of the ONL density, loss of rods outer segments (B) and epithelioid proliferation at the level of the RPE layer (C, p) associated with infiltration of melanophages (m).
These observations are of utmost importance, indicating that, in this model, Stakel did not diffuse from the choroidal vessels and did not cause harmful side effects in the surrounding tissues during PDT.

In contrast, even when nonocclusive verteporfin PDT parameters were used, immediate damage to the retina and RPE cell layer was detected. These severe RPE and retina lesions observed after verteporfin PDT may be related to two factors: (1) enhanced and easier diffusion of reactive oxygen species because of the induced exudative RPE detachment in these eyes and (2) diffusion of the verteporfin to the retina and its accumulation in the RPE cells, which may be the cause of extensive collateral damage to these tissues. ${ }^{22}$

Earlier studies in experimental animal models have reported the formation of immediate thrombi after verteporfin PDT. ${ }^{40}$ In our study, acute events of occlusive parameters showed choriocapillary endothelial cell damage, RPE change, and exudation, without evidence of acute vessel occlusion. Findings in more recent clinical studies hint that verteporfin PDT does not induce immediate thrombosis of CNV membranes but triggers exudation related to a breakdown of vascular barriers and the RPE pump. ${ }^{41}$ These latter observations are in accord with our present study findings.

Selectivity of PDT damage to the abnormal vessels is one of the crucial issues in the treatment of AMD. Among the palladium-substituted bacteriochlorophyll derivatives, WST-11 has many advantages other WST-09 (Tookad; Negma-Lerads), originally designed for cancer treatment ${ }^{42}$ and recently evaluated for choroidal occlusion in the rabbit eye. ${ }^{18}$ The half-life of WST-11 within the blood vessels is much shorter than that of

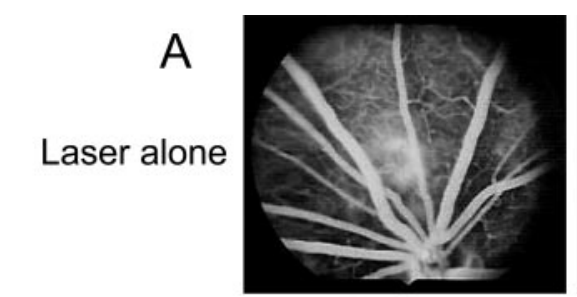

Before

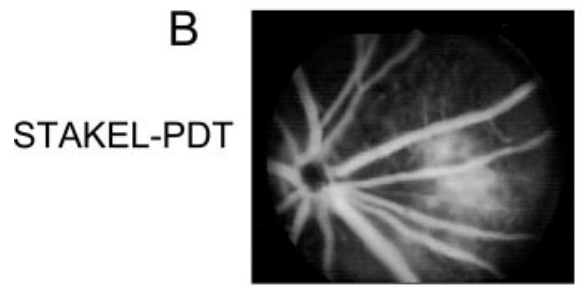

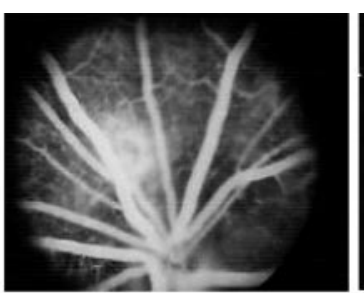

2 days

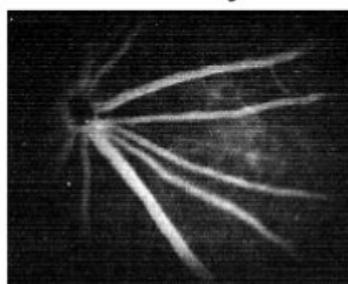

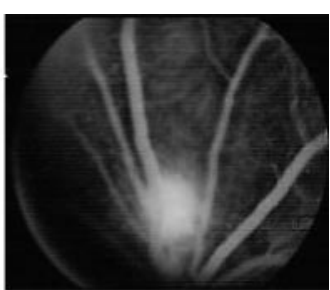

8 days

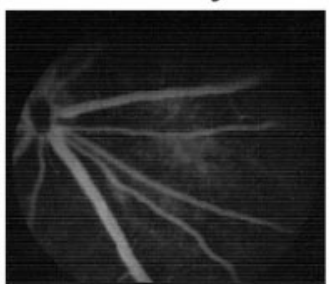

FiguRE 10. Fluorescein angiograms of rat eyes before and 2 and 8 days after Stakel PDT. Representative latephase FA of CNV treated either with control laser alone (A) or with Stakel PDT $5 \mathrm{mg} / \mathrm{kg}, 100 \mathrm{~J} / \mathrm{cm}^{2}$, and DLI 1 minute (B). Leaky lesions were observed before treatment in both control and treated eyes, but a significant reduction of leakage was observed in the Stakel-treated eye at 2 and 8 days, when compared with the lesion before treatment (B), whereas no significant decrease in leakage was observed at 2 and 8 days in the control eye (A). No occlusion of retinal vessels was observed after Stakel PDT in the treated area. 

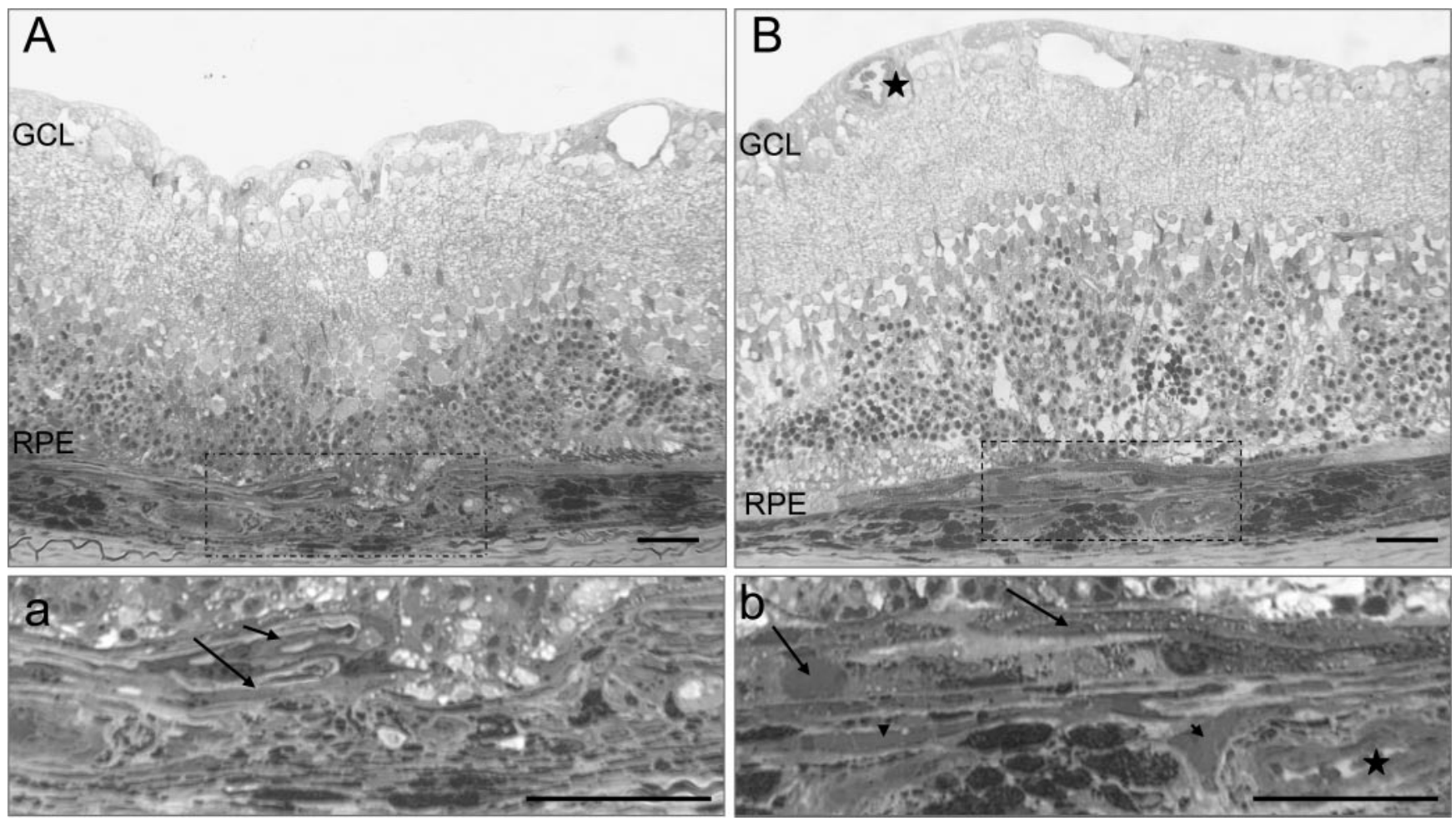

FIGURE 11. Semithin sections of CNV in the rat eye, 2 days after Stakel PDT with occlusive parameters $\left(5 \mathrm{mg} / \mathrm{m}^{2}\right.$, fluence $100 \mathrm{~J} / \mathrm{cm}^{2}$, and $1 \mathrm{minute}$ DLI). In the control illuminated retina, nonoccluded CNV (A, a, arrows) was observed. Two days after Stakel-PDT, occlusion of CNV was observed $(\mathbf{B}, \mathbf{b}$, arrows), as well as occlusion of the choriocapillaries within the treated spot (b, arrowheads). No occlusion of the retinal vessels (B, star) or of the large choroidal vessels (b, star) was observed in the treated area. At the border of the CNV, the RPE cell layer structure was well preserved $(\mathbf{B}, \mathbf{b})$.

WST-09 or verteporfin, as shown by its ability to induce vessel occlusion in a very short time (1-5 minutes) after IV injection. In fact, vessel occlusion with Stakel was induced by a DLI of 10 minutes or longer. With WST-09, on the other hand, occlusion of blood vessels was induced even after a DLI of 60 minutes. Moreover, low WST-09 induced RPE lesions even in the absence of choroidal vessel occlusion. ${ }^{18}$ As our study shows, these characteristics of WST-09 are similar to those of verteporfin. Because of its high-affinity binding to albumin WST-11 stays in the vascular compartment, with minimal distribution to peripheral tissues. Thus, Stakel appears to be a good candidate for a targeted and more selective treatment of $\mathrm{CNV}$.

Preliminary results obtained in the rat eye model of $\mathrm{CNV}$ with selected Stakel occlusive parameters confirmed that it is possible to close choroidal neovessels without closing deep choroidal vessels or retinal vessels and without major damage to RPE cells or retina. Indeed, as early as 2 days after CNV occlusion, no fluid accumulation was observed in the retina or under it. These CNV-selective effects indicate that Stakel PDT may have potential clinical applications. A more detailed evaluation of the effect of Stakel PDT in different models of neovessels is the subject of ongoing studies in our laboratory and will be published separately.

Palladium-substituted bacteriochlorophyll derivatives are very efficient photosensitizers. Depending on their chemical structures and charges, their protein binding and pharmacokinetics can be modified. WST-11 has been specifically designed for a vascular-targeted PDT of new vessels within the ocular tissues. The data obtained during this study indicate that this purpose has been fulfilled and that the collateral damage to the retina or RPE is minimal. Stakel PDT performance in animal models of angiogenesis and its efficacy and selectivity on $\mathrm{CNV}$ induced in the monkey eye will provide further insight into its potential use in the clinic.

\section{References}

1. Photodynamic therapy of subfoveal choroidal neovascularization in age-related macular degeneration with verteporfin: one-year results of 2 randomized clinical trials: TAP report-treatment of age-related macular degeneration with photodynamic therapy (TAP) Study Group. Arch Ophthalmol. 1999;117(10):1329-1345.

2. Bressler NM. Photodynamic therapy of subfoveal choroidal neovascularization in age-related macular degeneration with verteporfin: two-year results of 2 randomized clinical trials-TAP report 2. Arch Ophthalmol. 2001;119(2):198-207.

3. Blumenkranz MS, Bressler NM, Bressler SB, et al. Verteporfin therapy for subfoveal choroidal neovascularization in age-related macular degeneration: three-year results of an open-label extension of 2 randomized clinical trials-TAP Report no. 5. Arch Ophthalmol. 2002 Oct; $120(10): 1307-14$

4. Meads $\mathrm{C}$, Hyde C. Photodynamic therapy with verteporfin is effective, but how big is its effect? - results of a systematic review. $\mathrm{BrJ}$ Ophthalmol. 2004;88(2):212-217.

5. Brown DM, Kaiser PK, Michels M, et al. Ranibizumab versus verteporfin for neovascular age-related macular degeneration. $N$ Engl J Med. 2006;355(14):1432-1444.

6. Dougherty TJ, Gomer CJ, Henderson BW, et al. Photodynamic therapy. J Natl Cancer Inst. 1998;90(12):889-905.

7. Krammer B. Vascular effects of photodynamic therapy. Anticancer Res. 2001;21(6B):4271.

8. Moshfeghi DM, Kaiser PK, Grossniklaus HE, et al. Clinicopathologic study after submacular removal of choroidal neovascular membranes treated with verteporfin ocular photodynamic therapy. Am J Ophthalmol. 2003;135(3):343-350.

9. Tzekov R, Lin T, Zhang KM, et al. Ocular changes after photodynamic therapy. Invest Ophthalmol Vis Sci. 2006;47(1):377-385. 
10. Ozdemir H, Karacorlu SA, Karacorlu M. Early optical coherence tomography changes after photodynamic therapy in patients with age-related macular degeneration. Am J Opbthalmol. 2006;141(3): 574-576.

11. Oner A, Karakucuk S, Mirza E, Erkilic K. Electrooculography after photodynamic therapy. Doc Ophthalmol. 2005;111(2):83-86.

12. Mayo GL, Melendez RF, Kumar N, McKinnon SJ, Glickman RD. Antibody-targeted photodynamic therapy. Am J Opbthalmol. 2003;136(6):1151-1152.

13. Mori K, Yoneya S, Anzail K, et al. Photodynamic therapy of experimental choroidal neovascularization with a hydrophilic photosensitizer: mono-L-aspartyl chlorin e6. Retina. 2001;21(5):499508.

14. Huang Y, Obana A, Gohto Y, Nakajima S. Comparative study of the phototoxicity of two chlorin type photosensitizers, ATX-S10(Na) and verteporfin, on vascular endothelial and retinal pigment epithelial cells. Lasers Surg Med. 2004;34(3):216-226.

15. Hikichi $T$, Mori $F$, Nakajima $S$, et al. Dynamic observation of selective accumulation of a photosensitizer and its photodynamic effects in rat experimental choroidal neovascularization. Retina. 2001;21(2):126-131.

16. Chen Q, Huang Z, Luck D, et al. Preclinical studies in normal canine prostate of a novel palladium-bacteriopheophorbide (WST09) photosensitizer for photodynamic therapy of prostate cancers. Photochem Photobiol. 2002;76(4):438-445.

17. Brun PH, DeGroot JL, Dickson EF, Farahani M, Pottier RH. Determination of the in vivo pharmacokinetics of palladium-bacteriopheophorbide (WST09) in EMT6 tumour-bearing Balb/c mice using graphite furnace atomic absorption spectroscopy. Photochem Pbotobiol Sci. 2004;3(11-12):1006-1010.

18. Framme C, Sachs HG, Flucke B, Theisen-Kunde D, Birngruber R. Evaluation of the new photosensitizer Tookad (WST09) for photodynamic vessel occlusion of the choroidal tissue in rabbits. Invest Ophthalmol Vis Sci. 2006;47(12):5437-5446.

19. Mazor O, Brandis A, Plaks V, et al. WST11, a novel water-soluble bacteriochlorophyll derivative: cellular uptake, pharmacokinetics, biodistribution and vascular-targeted photodynamic activity using melanoma tumors as a model. Photochem Photobiol. 2005;81(2): 342-345.

20. Brandis A, Mazor O, Neumark E, Rosenbach-Belkin V, Salomon Y, Scherz A. Novel water-soluble bacteriochlorophyll derivatives for vascular-targeted photodynamic therapy: synthesis, solubility, phototoxicity and the effect of serum proteins. Pbotochem Pbotobiol. 2005;81:983-993.

21. Vakrat-Haglili Y, Weiner L, Brumfeld V, et al. The microenvironment effect on the generation of reactive oxygen species by Pd-bacteriopheophorbide. J Am Chem Soc. 2005;127:6487-6497.

22. Haimovici R, Kramer M, Miller JW, et al. Localization of lipoprotein-delivered benzoporphyrin derivative in the rabbit eye. Curr Eye Res. 1997;16(2):83-90.

23. Zacks DN, Ezra E, Terada Y, et al. Verteporfin photodynamic therapy in the rat model of choroidal neovascularization: angiographic and histologic characterization. Invest Ophthalmol Vis Sci. 2002; 43(7):2384-9128.

24. Kramer M, Miller JW, Michaud N, et al. Liposomal benzoporphyrin derivative verteporfin photodynamic therapy: selective treatment of choroidal neovascularization in monkeys. Ophthalmology. $1996 ; 103(3): 427-438$
25. Petermeier K, Tatar O, Inhoffen W, et al. Verteporfin photodynamic therapy induced apoptosis in choroidal neovascular membranes. Br J Ophthalmol. 2006;90(8):1034-1039.

26. Renno RZ, Delori FC, Holzer RA, Gragoudas ES, Miller JW. Photodynamic therapy using Lu-Tex induces apoptosis in vitro, and its effect is potentiated by angiostatin in retinal capillary endothelial cells. Invest Ophthalmol Vis Sci. 2000;41:3963-3971.

27. Tatar O, Adam A, Shinoda K, et al. Expression of VEGF and PEDF in choroidal neovascular membranes following verteporfin photodynamic therapy. Am J Opbthalmol. 2006;142(1):95-104.

28. Tatar O, Shinoda K, Adam A, et al. Effect of verteporfin photodynamic therapy on endostatin and angiogenesis in human choroidal neovascular membranes. Br J Opbthalmol. 2007;91(2):166-173.

29. Arnold JJ, Blinder KJ, Bressler NM, et al. Acute severe visual acuity decrease after photodynamic therapy with verteporfin: case reports from randomized clinical trials-TAP and VIP report no. 3 . Am J Opbthalmol. 2004;137(4):683-696.

30. Brown DM, Kaiser PK, Michels M, et al., for the ANCHOR Study group. Ranibizumab versus verteporfin for neovascular age related macular degeneration. N Engl J Med. 2006;355:1432-1444.

31. Kourlas H, Abrams P. Ranibizumab for the treatment of neovascular age-related macular degeneration: a review. Clin Ther. 2007; 29(9): $1850-1861$.

32. Novack GD. Pharmacotherapy for the treatment of choroidal neovascularization due to age-related macular degeneration. Annu Rev Pharmacol Toxicol. 2008;48-61-78.

33. Brown DM, Regillo CD. Anti-VEGF agents in the treatment of neovascular age-related macular degeneration: applying clinical trial results to the treatment of everyday patients. Am J Ophthalmol. 2007;144(4):627-637.

34. Kliman GH, Puliafito CA, Grossman GA, Gregory WA. Retinal and choroidal vessel closure using phthalocyanine photodynamic therapy. Lasers Surg Med. 1994;15:11-18.

35. Peyman GA, Moshfeghi DM, Moshfeghi A, et al. Photodynamic therapy for choriocapillaris using tin ethyl etiopurpurin (SnET2). Ophthalmic Surg Lasers. 1997;28:409-417.

36. Kazi AA, Peyman GA, Unal M, et al. Threshold power levels for Npe6 photodynamic therapy. Opbthalmic Surg Lasers. 2000;31: 136-142.

37. Obana A, Gohto Y, Kanai M, Nakajima S, Kaneda K, Miki T. Selective photodynamic effects of the new photosensitizer ATXS10(Na) on choroidal neovascularization in monkeys. Arch Ophthalmol. 2000;118(5):650-658.

38. Obana A, Gohto Y, Kaneda K, Nakajima S, Miki T. PDT to monkey CNV with ATX-S10(Na): inappropriateness of early laser irradiation for selective occlusion. Invest Opbthalmol Vis Sci. 2001;42:26392645.

39. El-Missiry MA, Abou-Seif M. Photosensitization induced reactive oxygen species and oxidative damage in human erythrocytes. Cancer Lett. 2000;158(2):155-163.

40. Schmidt-Erfurth U, Hasan T, Gragoudas E, Michaud N, Flotte TJ, Birngruber R. Vascular targeting in photodynamic occlusion of subretinal vessels. Ophthalmology. 1994;101(12):1953-1961.

41. Michels S, Schmidt-Erfurth U. Sequence of early vascular events after photodynamic therapy. Invest Opbthalmol Vis Sci. 2003; 44(5):2147-2154.

42. Woodhams JH, MacRobert AJ, Novelli M, Bown SG. Photodynamic therapy with WST09 (Tookad): quantitative studies in normal colon and transplanted tumours. Int J Cancer. 2006;118(2):477482 